AROUEOLOGÍA Y SOCIEDAD

№ 26, 2013: 419-446

ISSN: 0254-8062

RECIBIDO: 18 / ABR. / 2013

ACEPTADO: 30 / MAY. / 2013

\title{
ETNOARQUEOLOGÍA EN UN BARRIO TRADICIONAL DE AYACUCHO, A PARTIR DE LABORES DE MONITOREO ARQUEOLÓGICO
}

\author{
ISMAEL PÉREZ CALDERÓN \\ UNIVERSIDAD NACIONAL DE SAN CRISTÓBAL DE HUAMANGA \\ zismaelunsch@hotmail.com
}

\section{RESUMEN}

Presentamos información arqueológica, etnohistórica y etnográfica para conocer y entender las raíces culturales del barrio de Santa Ana en Ayacucho, establecido en un área con ocupación humana desde el periodo Formativo , según evidencias de cultura material registrada en los asentamientos cercanos de Pilacucho, Andamarca, Waychaupampa y en el mismo barrio de Santa Ana, cuya plaza trazada en la época colonial se encuentra sobre vestigios de las culturales Huarpa y Wari, durante esta última época los pobladores se dedicaron a la producción alfarera, algo semejante de lo que venía ocurriendo en los poblados de Conchopata y Acuchimay. Se hace referencia de afloramientos de arcilla en la misma plaza y alrededores los cuales debieron ser utilizados como canteras: presencia de entierros humanos en tumbas con paredes de piedra y en simples pozos excavados en suelo estéril como parte de un sector funerario y de los restos de un basural con abundante cerámica Wari, disperso en el subsuelo del ángulo noreste del referido espacio abierto.

Palabras Clave: Ocupación cultural, Huarpa, Wari, contextos funerarios, producción de cerámica, poblados menores.

\begin{abstract}
We present archaeological, ethnohistorical and ethnographic to know and understand the cultural roots of the Santa Ana in Ayacucho, established in an area with human occupation since at least the Formative period, according to material culture evidence recorded in the nearby settlements of Pilacucho, Andamarca Waychaupampa and in the neighborhood of Santa Ana, whose square drawn in the colonial era is on the cultural vestiges Huarpa and Wari, during this last period the inhabitants were devoted to the production of pottery, something similar to what was happening in villages and Acuchimay Conchopata. Reference is made of clay outcrops and around the square which had to be used as quarries, presence of human burials in tombs with stone walls and simple pits dug into sterile soil as part of a funeral industry, and remains a midden with abundant ceramic with a high proportion Wari dispersed in the basement of the northeast corner of said open space.
\end{abstract}

KEYWORDS: Cultural occupation, the Huarpa nobility, Wari, funerary contexts, ceramic production, sma- 


\section{INTRODUCCIÓN}

Hacemos uso de la etnoarqueología por tratarse de un barrio excepcionalmente artesanal, dedicado fundamentalmente a la producción del arte textil desde la época colonial según fuentes documentales alcanzados por la historia, seguido del trabajo en piedra de Huamanga y retablos que han opacado la producción de cerámica relegada a tercer plano por la rentabilidad económica, frente a la artesanía de Quinua, la cual ha cobrado mayor popularidad, aun cuando la arqueología no haya logrado encontrar evidencias de agrupaciones alfareras establecidas en el mismo pueblo, como para sostener que el presente sirve de referente para reconstruir el pasado. En el caso de Santa Ana las evidencias primarias provienen de la fuente arqueológica, evidencian que la antigua población prehispánica estuvo dedicada a la fabricación de cerámica, tradición que se ha ido perdiendo pero que sirve de soporte para afirmar que el pasado sirve para estudiar al presente en la mediada de que en la actualidad hay una sola familia dedicada a producción de cerámica. Entonces no es un cliché, como sostiene Binford (1998), decir que estudiamos al pasado para conocer el presente y advertir el futuro como es la perdida de la tradicional producción de cerámica en el barrio de Santa Ana.

En mayo del 2009 fuimos invitados por la Municipalidad Provincial de Huamanga para asumir las labores de monitoreo arqueológico en la obra: Construcción, pavimentación de vías, construcción de veredas, y tratamiento de la plaza Santa Ana, distrito de Ayacucho, provincia de Huamanga-Ayacucho, en el marco del proyecto La calle de mi barrio, programa integral de mejoramiento de barrios y pueblos, promovido a nivel nacional por la Presidencia de la Republica, financiada por el Ministerio de Vivienda, Construcción y Saneamiento, a través de la Municipalidad Provincial de Huamanga, que había iniciado la obra sin monitoreo arqueológico, hecho lo que dio lugar a una necesaria intervención que coincidía con el reclamo de algunos pobladores que presenciaban la remoción del terreno y la presencia de restos arqueológicos entre cantaros, ollas, batanes y piedras de río conforme se iba retirando la estructura de cemento del piso que lucia hasta aquel entonces la plaza del barrio de Santa Ana considerado como uno de los más antiguos de Ayacucho virreinal.

Lo primero que hicimos fue examinar los perfiles de las zanjas, pozos, cortes y áreas removidas del terreno en todo el contorno de la plaza incluyendo veredas, luego seleccionamos algunos puntos para el registro de la formación estratigráfica formada sobre el suelo estéril, el cual se encuentra a 50 $\mathrm{cm}$ de profundidad en el lado sur y más de $3 \mathrm{~m}$ en el lado norte lo que explica el declive que presenta la plaza desde su formación como tal en la época virreinal con la edificación de la iglesia sobre los vestigios de un asentamiento de la época Huari, donde sin duda el lado norte de la plaza es el espacio con mayor concentración de evidencias arqueológicas, de donde precisamente provienen los hallazgos que a continuación pasamos a detallar, no sin antes ofrecer un breve panorama sobre la historia del barrio de Santa Ana en el contexto de la ciudad de Ayacucho como preámbulo para conocer y entender el cuidado y mejoramiento del patrimonio histórico monumental de la nación, con proyectos que coadyuven a elevar el nivel de vida social y económica de la población que cuenta con un vasto y rico potencial artesanal aún no aprovechado en su verdadera dimensión.

\section{Santa Ana antes de la fundación de Huamanga}

Estudios arqueológicos efectuados en el valle de Huamanga [Lumbreras (1956, 1958, 1969,1974); Benavides (1976); MacNeish, García, Lumbreras, Vierra y Nelken-Terner (1981); González (1966, 1972); González, Gutiérrez y Urrutia (1995); Ochatoma (1985, 1992); Cabrera (1991); Alarcón (1990); Machaca (1997); Mancilla (2008), entre otros], demuestran que el área donde se encuentra el pueblo de Santa Ana forma parte de una zona rodeada de un conjunto de asentamientos con evidencias que señalan haberse establecido por lo menos desde el periodo Formativo (1500 a.C), como es el caso de la cerámica dispersa en los barrios de La Unión, Piladucho, Andamarca, Belén, Qarqampata y Ayaorqo, en la margen izquierda del río Alameda donde los españoles construyeron la vieja ciudad de Huamanga 
(hoy Ayacucho). Estos primeros establecimientos corresponden a poblaciones aldeanas dedicadas a la agricultura y ganadería, relacionadas con las primeras construcciones de canales y andenes, a la vez que representan las primeras evidencias vinculadas con la introducción de la cerámica, textilería y otras manualidades que siguen vigentes en la práctica cotidiana y la memoria colectiva de los actuales pobladores.

La presencia de restos de cerámica, óseos y artefactos líticos en las paredes de las viviendas construidas de adobe, piedra y tapial; en el corte del terreno de algunas calles y en el espacio que ocupa la misma plaza de Santa Ana, indican claramente como desde la época colonial se viene alterando el terreno arqueológico con la construcción de cada vez mayor de viviendas modernas, remodelación de calles y otros espacios abiertos con ladrillo y cemento, sin que se haya efectuado el mínimo registro de las evidencias prehispánicas, siendo ahora un reto para la investigación arqueológica documentar lo que aún queda en las construcciones tradicionales y espacios de circulación adjuntos.

De un breve examen de la cerámica y el material pétreo que forma parte de las paredes de las viviendas de adobe y tapial podemos confirmar que la zona fue ocupada desde los periodos Formativo (1500 a.C.) hasta Wari (1100 d.c.), tiempo en que no solamente creció la población aprovechando los recursos naturales de su entorno sino que modificaron el paisaje con el trazo y construcción de complejos sistemas de obras hidráulicas (canales, andenes, reservorios, etc.) y del urbanismo como Ñawimpuquio y Conchopata, tal como se puede deducir del material pétreo utilizado para la construcción de la referidas viviendas tradicionales.

\section{SANTA ANA DESDE la ÉPOCA VIRREINAL}

Después de la fundación de Huamanga (1540), don Francisco Toledo, basado en la existencia de agrupaciones de indígenas en las cercanías donde se trazó la ciudad, ordenó la formación de dos parroquias, la de María Magdalena (Urin barrio) y Santa Ana (Hanan barrio), González, Huertas y Rivera (1980) y Huertas (1981). Por otro lado se tiene conocimiento que Santa Ana es la sexta iglesia, fundada en 19 de abril de 1569, la cual fue construida por los indios de Andamarca (Mancilla 1987).

En 1572, el Virrey ordenó al corregidor de la ciudad don Pedro de Mercado y Peñaloza y don Jerónimo de Silva, visitar ambas parroquias, quienes informan que en cada parroquia había ayllus donde vivían indígenas que estaban divididos en yanaconas y cañaris quienes llegaron junto con los españoles. Los cañaris estuvieron ubicados en Hanan Parroquia considerados como indios privilegiados, razón por la que no pagaban tributos ni realizaban mitas en las minas, lo que posibilitó para que esta población se dedicara a la actividad artesanal de carácter familiar.

Una vez construida la iglesia, alrededor de 1609, Santa Ana fue considerada como el segundo curato del obispado de Huamanga y reconocida mediante la Bula del Papa Pablo V y confirmada a través de Cedula Real. Pese a este privilegio, muchos de los corregidores pretendieron desconocer y obligar a tributar lo que dio lugar a frecuentes levantamientos, sin embargo fueron enrolados a las filas del clero de la cristiandad donde tributaban todos los ayllus.

Durante la conquista fue uno de los asentamientos humanos de mayor población por su privilegio de haber llegado junto con los españoles y no pagar tributo y las condiciones de abundancia de agua que surcaba su jurisdicción, extendiéndose a los actuales barrios de Puca Cruz y Andamarca. En la época republicana deviene en una capellanía, la misma que comprendía: Sacsamarca, Rancha, Socos, Urubamba, Belén Soquiacato, Puca Cruz, San Juan Bautista, Carmen Alto y Andamarca, estos pobladores vinieron desligándose paulatinamente del ayllu de Santa Ana buscando su autodesarrollo tales como Carmen Alto y San Juan Bautista convirtiéndose posteriormente en distritos por decisión y gestión de sus moradores entre 1924 y 1960 respectivamente, Aliaga y Zevallos (1977). 
De acuerdo a los archivos de la comunidad de Santa Ana, en el año 1947 las autoridades iniciaron gestiones ante las instancias respectivas para convertirse en Comunidad, sin el resultado esperado, debido a que su Población Económicamente Activa (PEA) se dedicaba, en su mayoría, a la artesanía más no así a la agricultura, ni ganadería, requisitos indispensables para constituir una comunidad. En 1963 se reinicia la gestión contando con 412 moradores, después de dos años de exigencia al Ministerio de Agricultura, Zonal XVI, es reconocida como Comunidad bajo resolución № 025-1965. Posteriormente en 1969 sus autoridades comunales gestionan la conversión en distrito, gestión que no ha prosperado hasta la fecha.

Actualmente la comunidad de Santa Ana cuenta con cerca de 7000 habitantes que constituye la Población Económicamente Activa (PEA), cuya base económica sigue siendo la producción y venta de artesanía en diferentes líneas: tejido de telar a pedal (introducido por los españoles y que se practica desde hace más de cuatro siglos), cerámica, tallado en piedra de Huamanga, peletería, hilado, tejido en telar a cintura y otras labores artesanales tradicionales que se complementan con actividades agrícolas y de ganadería. La comunidad es dueña de extensos terrenos y muchas familias, aparte de sus viviendas talleres poseen también terrenos dedicados al cultivo y crianza de animales.

\section{LA PLAZA Y SU ENTORNO}

Según el plano topográfico elaborado por José R. Ruiz Fowler (1924), la plaza de Santa Ana ocupa un espacio con un declive que baja del cerro Cabrapata, seccionada de sur a norte por de cauce temporal de las quebradas de Santa Ana y Huanchanta que confluyen en el río de la Alameda. A un lado de la plaza está la denominada Hanan Parroquia, junto con algunas viviendas que llegaban solo hasta las cuadras de las calles Madrid y Bolognesi, con amplios espacios libres que posteriormente se fueron urbanizando hacia los lados sureste y suroeste, mientras que el espacio de los lados opuestos aparece trazado en damero con más de 15 cuadras que tienen acceso a la proyección de las calles Libertad y Grau, que convergen en el tradicional plazoleta Cristóbal, junto al parque de Versalles o Sutucchaca para continuar por las calles Iglesias, Carvajal o Miguel Estete con las calles Cáceres, Gálvez e Inclan que conducen directamente a la plaza conocida también como Jerusalén.

Por lo menos hasta 1920, la plaza Santa Ana o Jerusalén mantenía el declive natural del terreno descendiente hacia el río de la Alameda, posteriormente fue nivelando con escombros traídos de asentamientos arqueológicos cercanos, aunque no se descarta que dicho material cultural correspondan a un antiguo asentamiento destruido para la construcción del templo Santa Ana o Hanan Parroquia.

\section{El MONITOREO ARQUEOLÓGICO}

Consistió en examinar las áreas removidas a mano y con maquinaria tanto de las veredas y como de la plaza, deteniéndose el avance en los espacios con indicios arqueológicos no identificadas a nivel de superficie. La mayoría de las veredas eran de tierra de manera que solo se niveló para formar los sardineles y veredas de cemento, las calles que circundan la plaza estaban hechas de cemento y los espacios para jardines, graderías, accesos y lozas de la nueva plaza en diferentes niveles respetando el declive original del terreno como el ángulo noreste que mantiene el mismo nivel desde la superficie. Examinamos el contenido cultural del terreno en busca de restos arquitectónicos y/o material asociado, para registrarlo en fichas y ubicarlo en un plano topográfico de la plaza.

De manera general, el lado sur presenta escasos restos arqueológicos mezclados con basura moderna en las distintas capas que forman un estrato de $60 \mathrm{~cm}$ de grosor sobre suelo estéril, mientras que en el ángulo noreste la estratigrafía tiene aproximadamente $2,5^{\circ}$ de grosor, con abundantes fragmentos de los estilos Kumunsenqa, Huarpa y Wari, depositados a manera de un basural adyacente a la planta de un molle que fue dejado en su propio sitio frente a la casa de la familia Gálvez. 


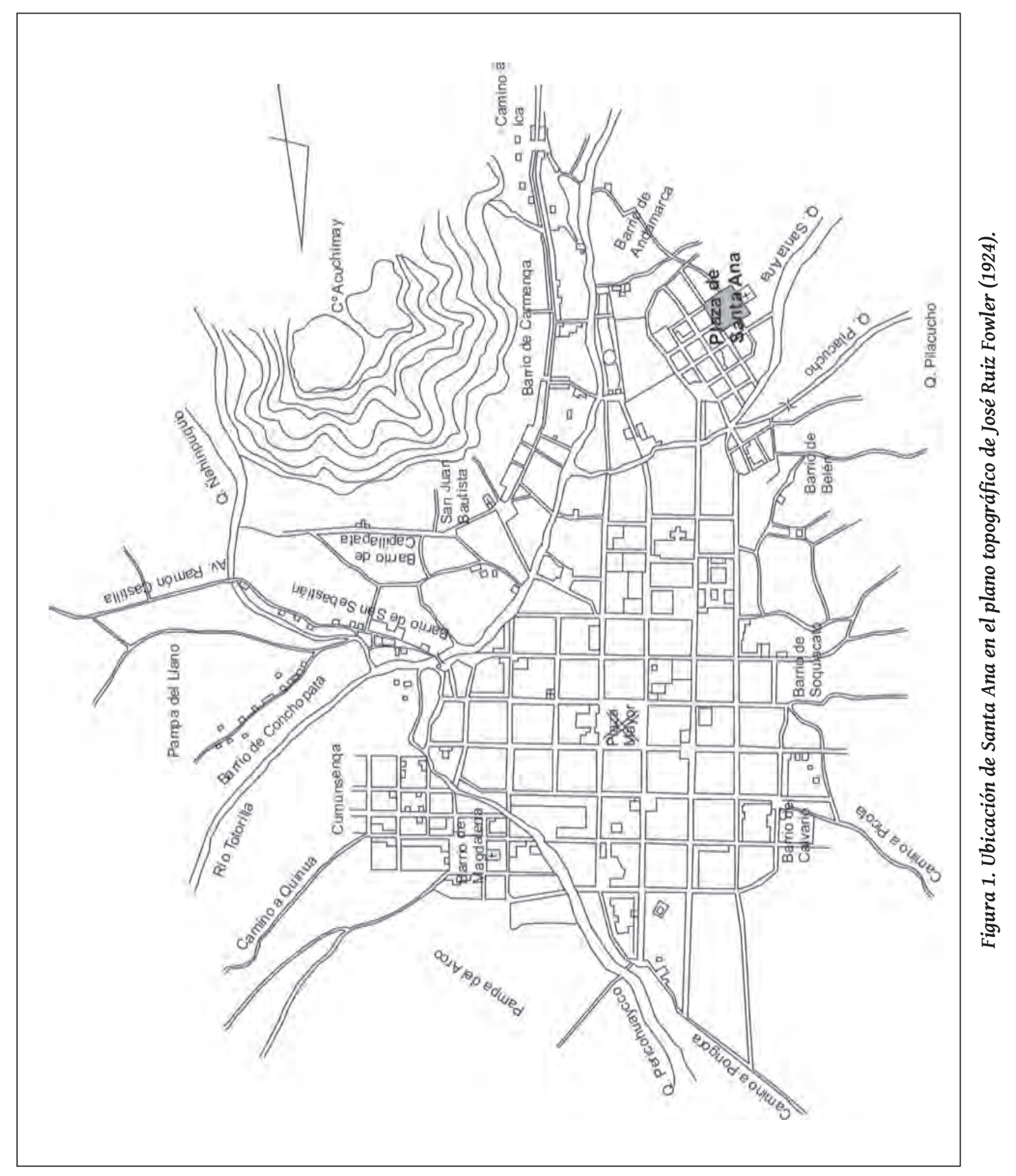




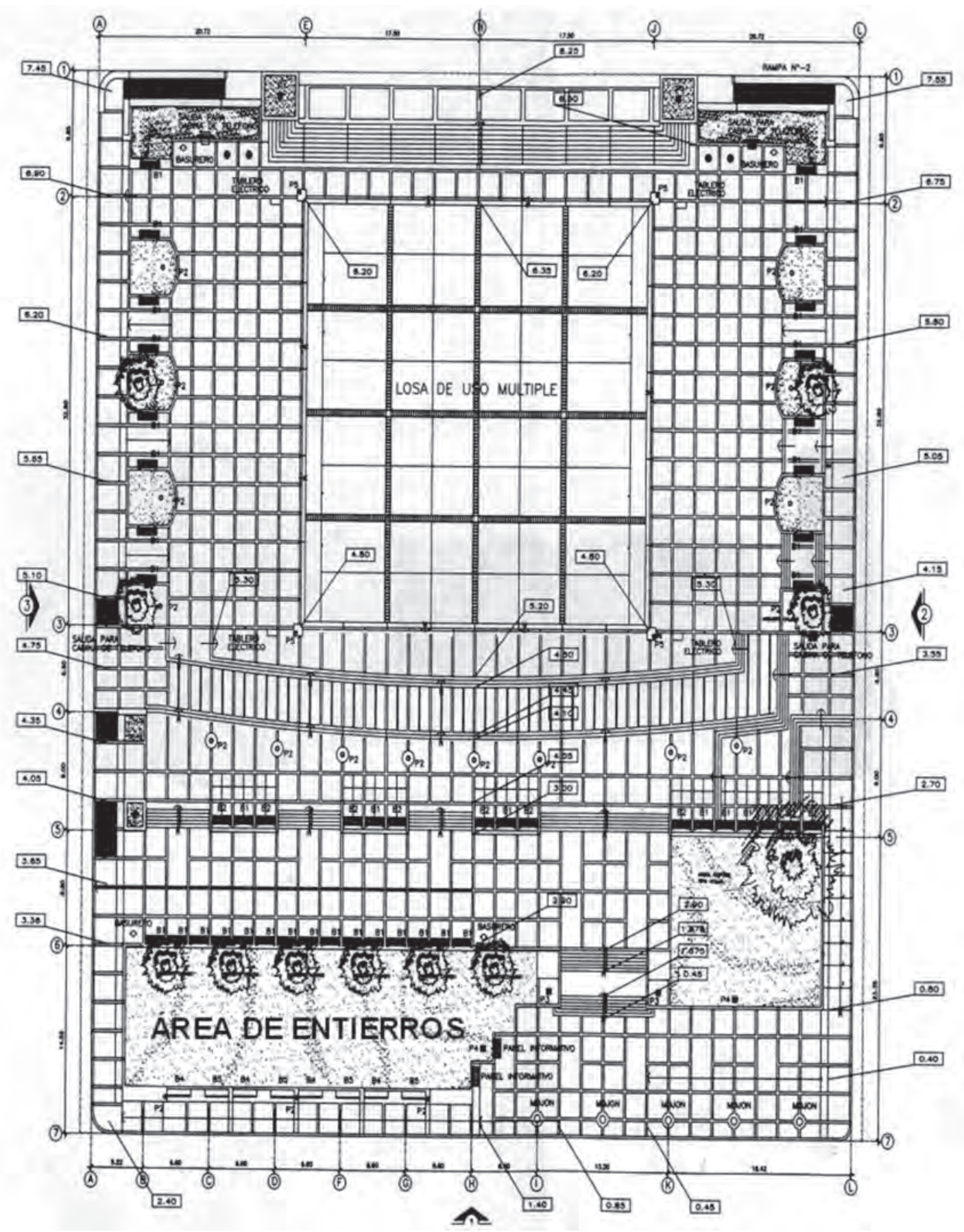

Figura 2. Plano de planta de exposición final de la plaza Santa Ana.

(Fuente Proyecto Municipalidad provincial de Huamanga 2009). 


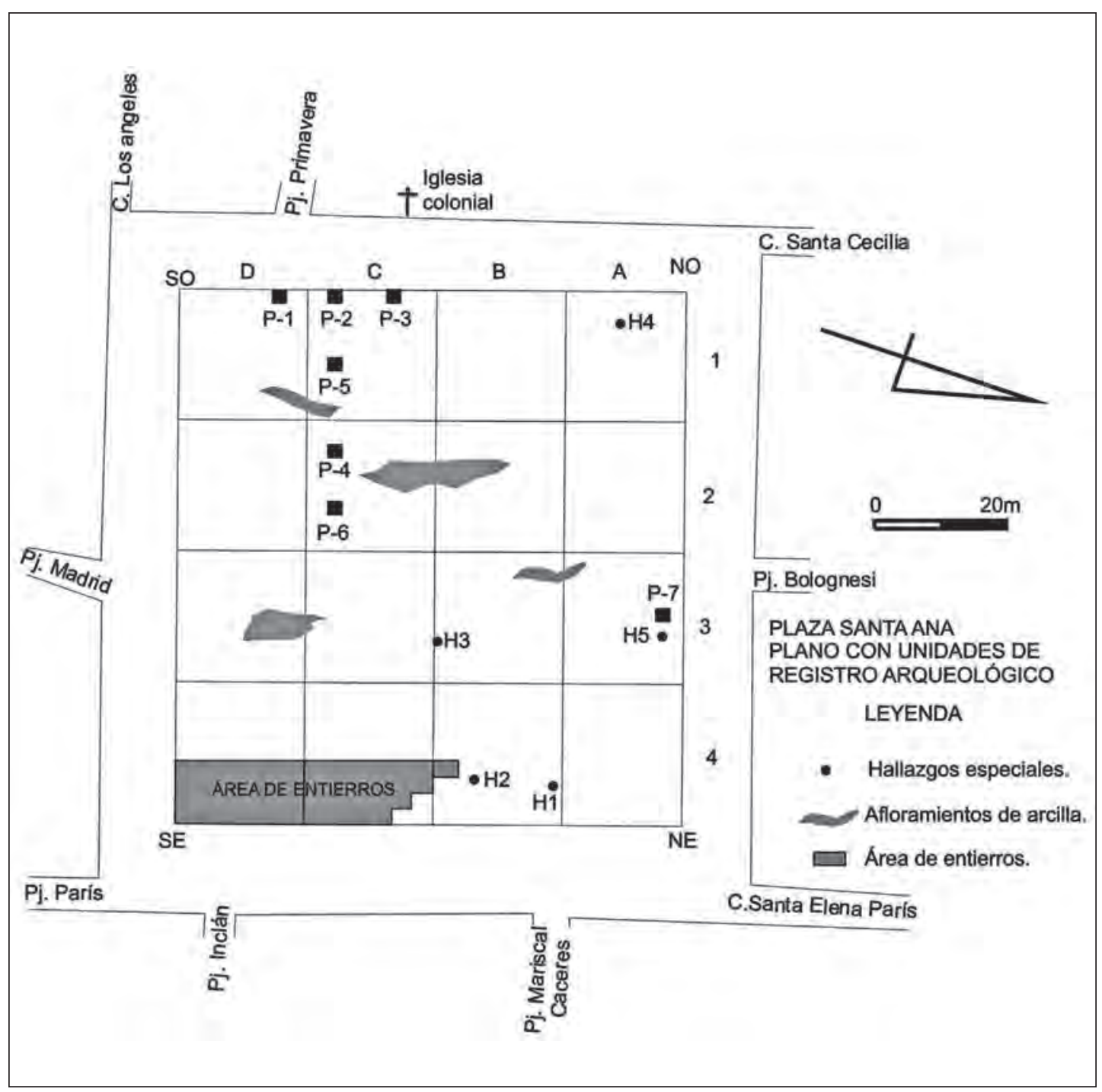

Figura 3. Plano de la plaza con trazado de unidades o cuadrantes para el registro arqueológico.

\section{REGISTRO ARQUEOLÓGICO}

Seleccionamos siete perfiles, tres paralelos a la fachada de la Iglesia, tres en el lado del jirón Mariscal Cáceres y uno en el lado que da a la vivienda de la familia Gálvez, tal como a continuación se explica:

\section{PERFIL 1}

Medidas : $1 \mathrm{~m}$ de ancho por 1,68 $\mathrm{m}$ de profundidad.

Ubicación : Unidad 1C.

Fecha : : Santa Ana, 16 junio 2009.

Dibujo : Angélica Canchari Castro. 


\section{Deposición estratigráfica}

S. Superficie nivel de la calle.

1. Concreto.

2. Capa de forma alargada de color beige, de consistencia compacta y granulometría fina, con presencia de material orgánico (raíces) en escasa proporción.

3. Capa de color gris claro con inclusión de piedras de menor tamaño, distribuidas a lo largo de la capa con presencia aún de material orgánico (raíces).

4. Capa de color gris claro de granulometría fina y de consistencia semicompacta.

5. Suelo estéril (arcilla de coloración blanquecina).

\section{PERFIL 2}

Medidas : $1 \mathrm{~m}$ de ancho por 2,26 m.

Ubicación : Unidad 1B.

Fecha : Santa Ana, 14 junio de 2009.

Dibujo : Angélica Canchari Castro.

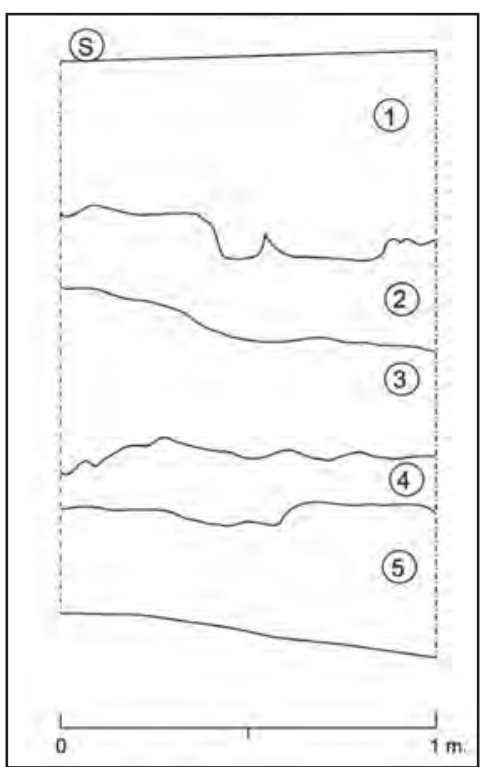

Figura 4. Estratigrafía del perfil 1.

\section{Deposición estratigráfica}

S. Superficie de la calle.

1. Concreto.

2. Tierra de color beige claro, de consistencia compacta y granulometría fina, con presencia de piedras menores en escasa proporción, acumuladas en la parte inferior de la capa.

3. Tierra de color marrón de consistencia compacta, granulometría fina con presencia de piedras pequeñas.

4. Capa de color gris, granulometría fina y de consistencia semicompacta.

5. Suelo estéril (arcilla blanquecina).

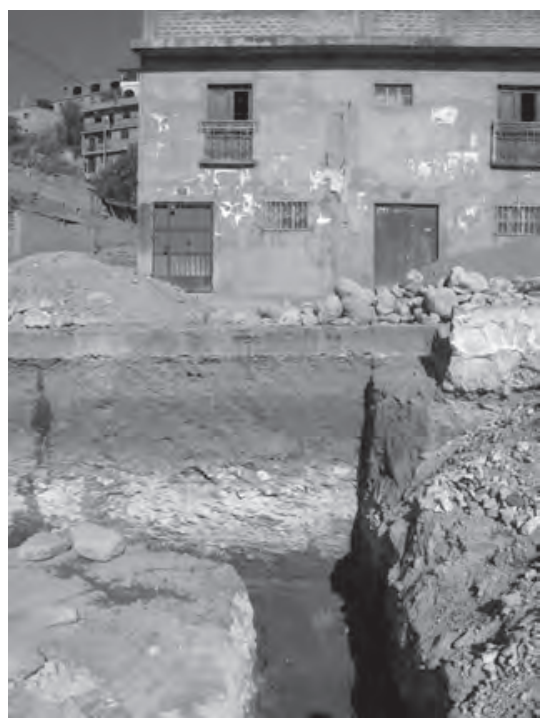

Figura 5. Perfil 2, lado suroeste de la plaza.

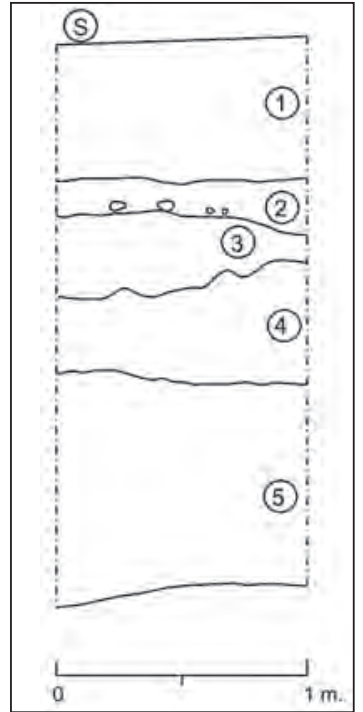

Figura 6. Estratigrafía del perfil 2. 


\section{PERFIL 3}

Medidas : $1 \mathrm{~m}$ de ancho por 1,70 $\mathrm{m}$ de profundidad.

Ubicación : Unidad 1C.

Fecha : Santa Ana, 16 junio de 2009.

Dibujo : Angélica Canchari Castro.

\section{Deposición estratigráfica}

S. Superficie de la calle.

1. Concreto.

2. Tierra de color beige claro, de consistencia suelta, granulometría fina con presencia de piedrecillas.

3. Arena con gran cantidad de piedrecillas y piedras menores distribuidas de manera regular y consistencia semicompacta.

4. Tierra de color beige de consistencia compacta.

5. Tierra blanquecina de consistencia compacta correspondiente a la roca madre.

\section{PERFIL 4}

Medidas : $2 \mathrm{~m}$ de largo por $1 \mathrm{~m}$ de profundidad.

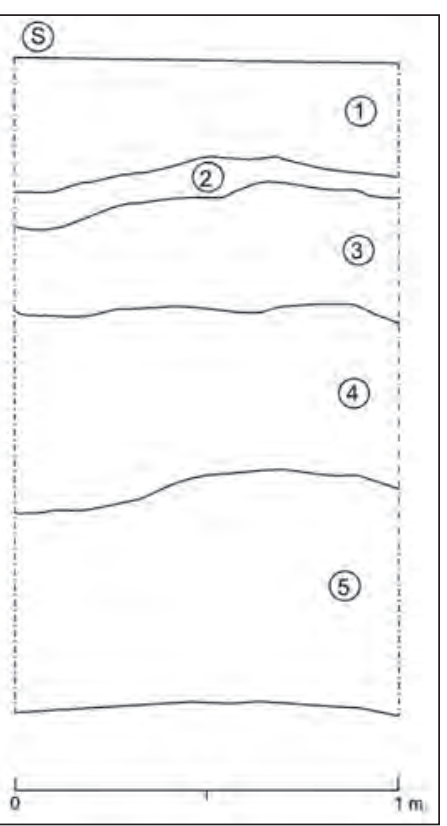

Figura 7. Estratigrafía del perfil 3.

Unidad : 4C.

Fecha : : Ayacucho, 18 junio de 2009.

Dibujo : Hamilton Paredes Huarcaya.

\section{Deposición estratigráfica}

S. Superficie relleno de tierra.

1. Capa de color beige de consistencia semicompacta y de $32 \mathrm{~cm}$ de espesor, con presencia de piedras de diferente tamaño, material orgánico (raíces) en escasa proporción.

2. Capa de $10 \mathrm{a} 12 \mathrm{~cm}$ de espesor, consistencia semicompacta es de color gris oscuro y presenta escaso material orgánico con piedras de menor tamaño, ésta capa presenta escaso material cultural que comprende tiestos de cerámica ubicadas en un extremo de la capa.

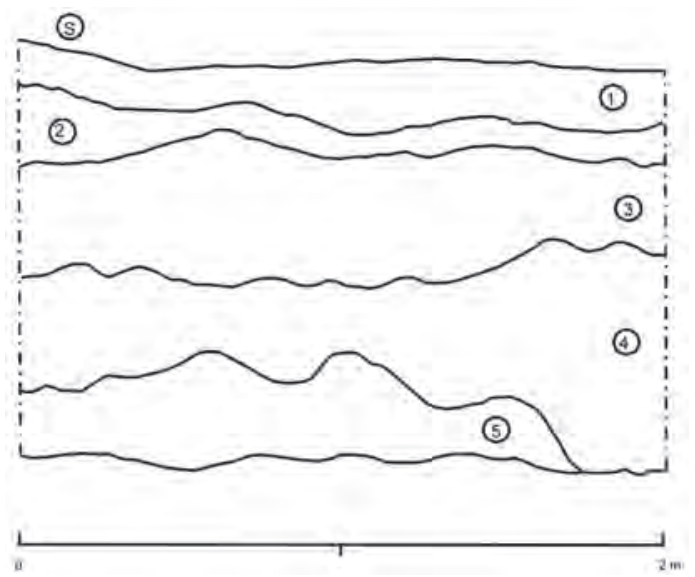

Figura 8. Estratigrafía del perfil 4.

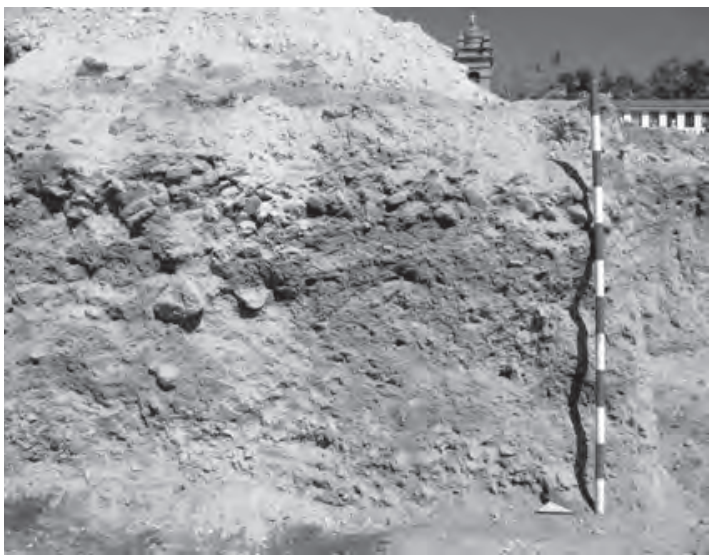

Figura 9. Detalle del perfil 4. 
3. Capa de 10 a $12 \mathrm{~cm}$ de espesor, consistencia semicompacta, color gris claro con gran cantidad de piedras de diferente tamaño distribuidas de manera regular en la capa, continua la presencia de material orgánico (raíces). El material cultural asociado es cerámica no decorada con pequeños trozos de carbón, distribuyen de manera regular en toda la capa.

4. Capa de consistencia semicompacta, color gris claro con presencia de manchas de color beige claro y manchas de color blanco.

5. Tierra compacta, granulometría fina, color beige oscuro sin material cultural, asentada sobre suelo estéril.

\section{PERFIL 5}

Medidas : $2 \mathrm{~m}$ de largo por 1,30 $\mathrm{m}$ de profundidad.

Ubicación : Unidad: 4C.

Fecha : Santa Ana, 18 de junio de 2009.

Dibujo : Irvin Galindo Mendieta.

\section{Deposición estratigráfica}

S. Superficie relleno de tierra.

1. Tierra de color gris oscuro de granulometría fina de consistencia compacta con inclusión de material orgánico (raíces) en la parte central de la capa y presencia de piedrecillas en escasa proporción.

2. Arena media con inclusión de piedras menores, la capa es de color beige claro de consistencia semicompacta, en la parte central del estrato se observa restos de un piso de diatomita.

3. Tierra de granulometría mediana, consistencia compacta, color entre gris claro- oscuro con inclusión de piedras de tamaño regular. Presenta fragmentos de cerámica Wari sin decorar dispersos a lo largo de capa.

4. Tierra de color beige oscuro de granulometría media y de consistencia compacta, con inclusión de pequeños y grandes bloques de piedra.

5. Arena fina con pequeñas piedras, consistencia semicompacta, color beige se proyecta en el subsuelo.

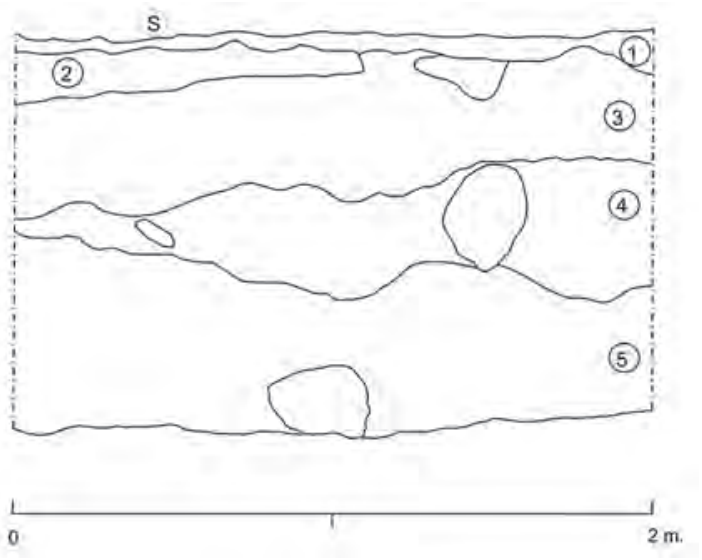

Figura 10. Estratigrafía del perfil 5.

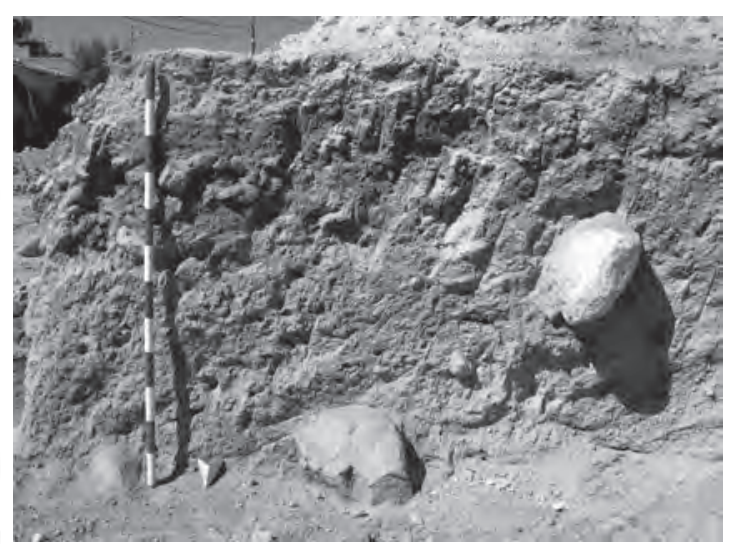

Figura 11. Detalle del perfil 5. 


\section{PERFIL 6}

Medidas : $2 \mathrm{~m}$ de ancho por 1,19 $\mathrm{m}$ de profundidad.

Ubicación : Unidad: 4C.

Fecha : Ayacucho, 18 de junio de 2009.

Dibujo : Angélica Canchari Castro.

\section{Deposición estratigráfica}

S. Superficie constituida por relleno de tierra suelta.

1. Tierra de color marrón claro y de consistencia compacta de granulometría fina, con pocos fragmentos de cerámica.

2. Tierra de color marrón oscuro, granulometría fina, consistencia compacta sin material cultural.

3. Tierra de granulometría fina, consistencia compacta, coloración blanquecina con inclusión de piedras pequeñas distribuidas a lo largo de toda la capa.

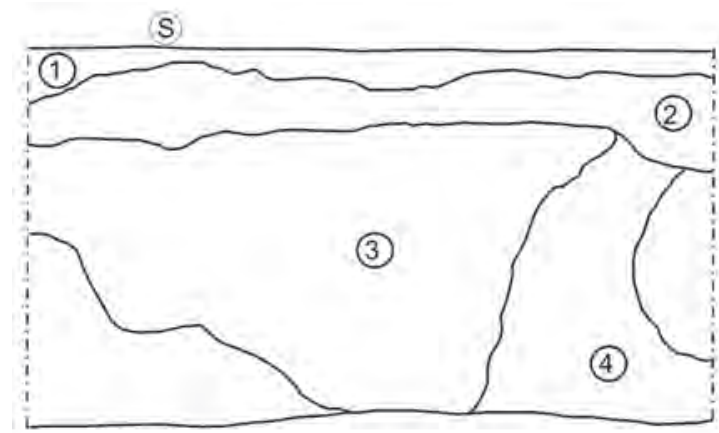

4. Tierra de color beige, granulometría fina con presencia de pequeñas piedras y otras de tamaño mediano, se proyecta en el subsuelo.

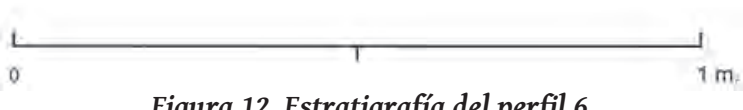

Figura 12. Estratigrafía del perfil 6.

\section{PERFIL 7}

Medidas : $5 \mathrm{~m}$ de largo por $80 \mathrm{~cm}$ de profundidad.

Unidad : 3D.

Fecha : Santa Ana, 20 de junio de 2009.

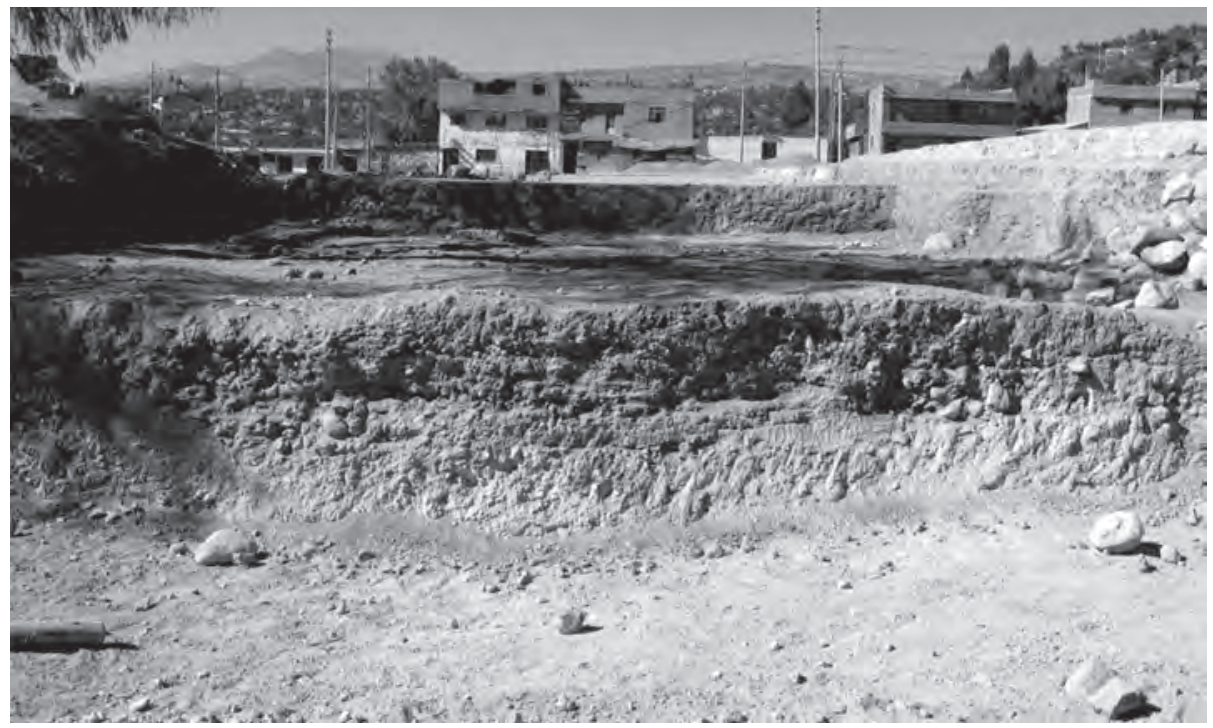

Figura 13. Vista del perfil 7 lado norte de la plaza. 


\section{Deposición estratigráfica}

S. Superficie compuesta por relleno de tierra.

1. Tierra de color gris claro, consistencia semicompacta de granulometría media.

2. Tierra de color gris claro, uniforme en casi toda la capa, granulometría fina y consistencia semi compacta: Esta capa presenta gran cantidad material cultural formado por fragmentos de cerámica Huarpa y Wari, con restos óseos en medio de raíces de molle.

3. Capa formado por piedras regular tamaño con tierra de color gris claro, el material cultural tiende a disminuir, aparece depositada sobre el suelo estéril (arcilla blanquecina).

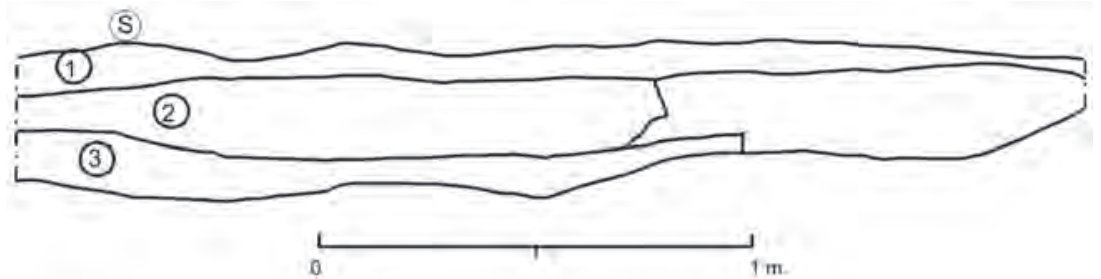

Figura 14. Dibujo estratigráfico del perfil 7, donde se aprecia las diferentes capas culturales sobre suelo estéril.

\section{Materiales Recuperados PREVio al Monitoreo}

En esta sección se da cuenta de algunos objetos fragmentados y enteros recuperados por el personal obrero durante la remoción de la Plaza antes de nuestra intervención. Dicho material cultural fue inventariado, indagando sobre la procedencia específica de cada objeto, dado a que aún seguían laborando el personal obrero que participó en la remoción del terreno, en esta acción recibimos el apoyo del equipo de ingeniería para ubicar en el plano a los diferentes hallazgos. A solicitud de los pobladores que vigilaron en todo momento los materiales arqueológicos extraídos así como los objetos recuperados de las tumbas disturbadas, el material fue depositado en el Museo de arte textil del sector de San José en el barrio de Santa Ana.

\section{HALLAZGO 1}

Ubicación : Unidad 4C.

Clase de objeto : Cántaro de $45 \mathrm{~cm}$ de alto, base plana y asas verticales, localizado a unos $5 \mathrm{~m}$ al este del hallazgo 2, contenía tierra con algunos fragmentos astillados de restos

Fecha de hallazgo : 6 de junio de 2009.

Comentario : Por la relación con la cerámica del hallazgo 2 se asocia a la época Wari como parte del entierro secundario con materiales arqueológicos traídos de lugares cercanos para nivelar el desnivel de la plaza.

\section{HALLAZGO 2}

Ubicación : Unidad 4C.

Clase de objetos : Fragmentos de cerámica prehispánica de un cántaro grande de base plana, fragmento de un cucharón de cerámica u un cuenco de estilo Wari Negro Decorado, esta última con restos de pintura de color rojo, junto a lo cual había un canto rodado con desgaste en los extremos.

Fecha de hallazgo : 5 de mayo de 2009.

Comentario : Los restos encontrados corresponden a un entierro secundario en el lado este de la plaza. Los restos de tierra de color rojo encontrado en el interior de la 
vasija indican la cercanía a talleres de producción de cerámica. El contexto formaba parte de la capa de relleno que nivelaba el extremo sureste de la plaza en dirección a la calle Mariscal Cáceres.
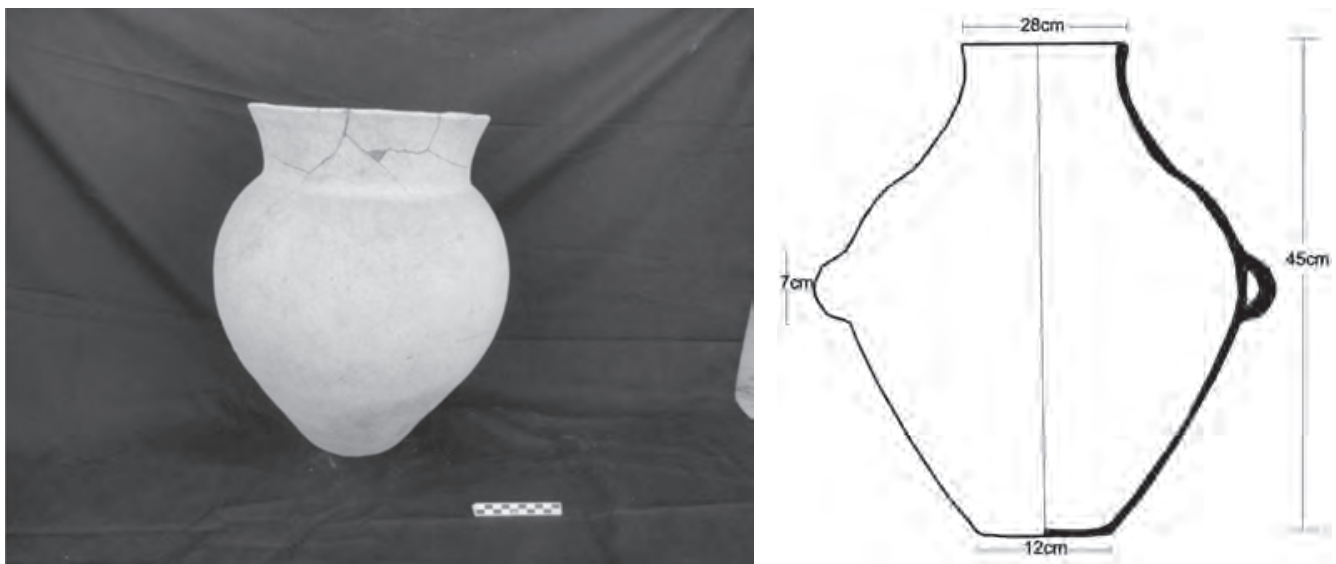

Figura 15. Foto y dibujo de cántaro Wari de una sola asa (hallazgo 1).
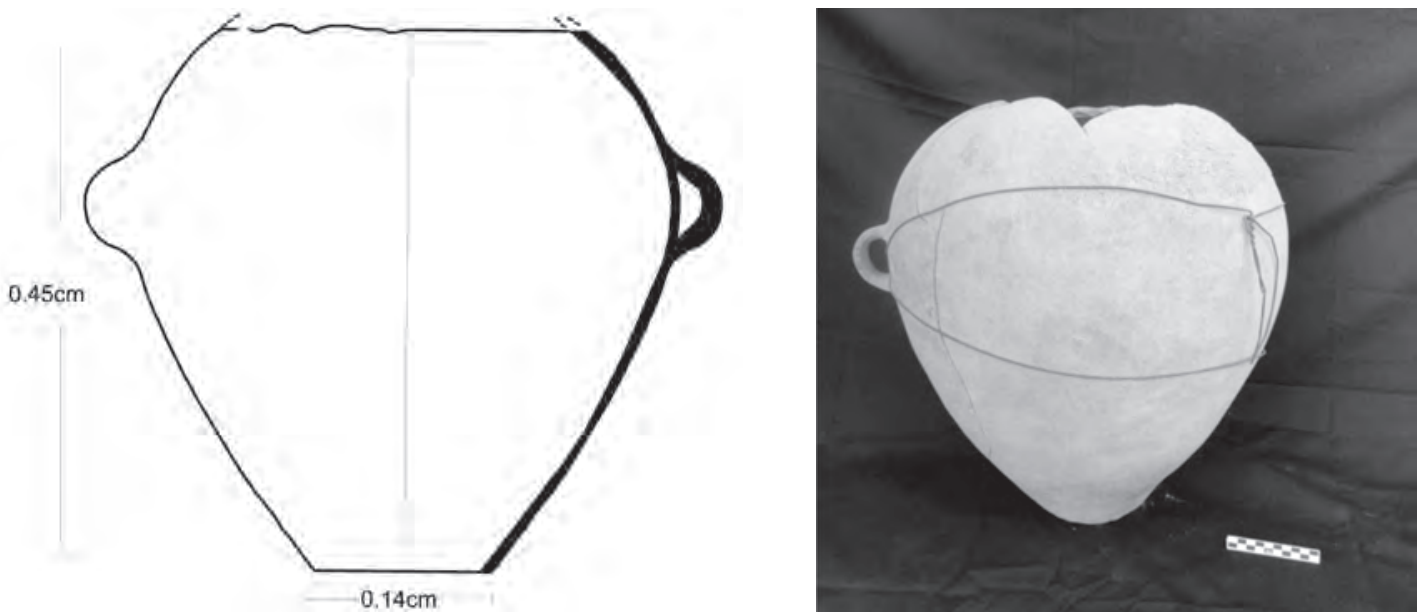

Figura 16. Dibujo y foto de cántaro Wari de una asa (hallazgo 2).
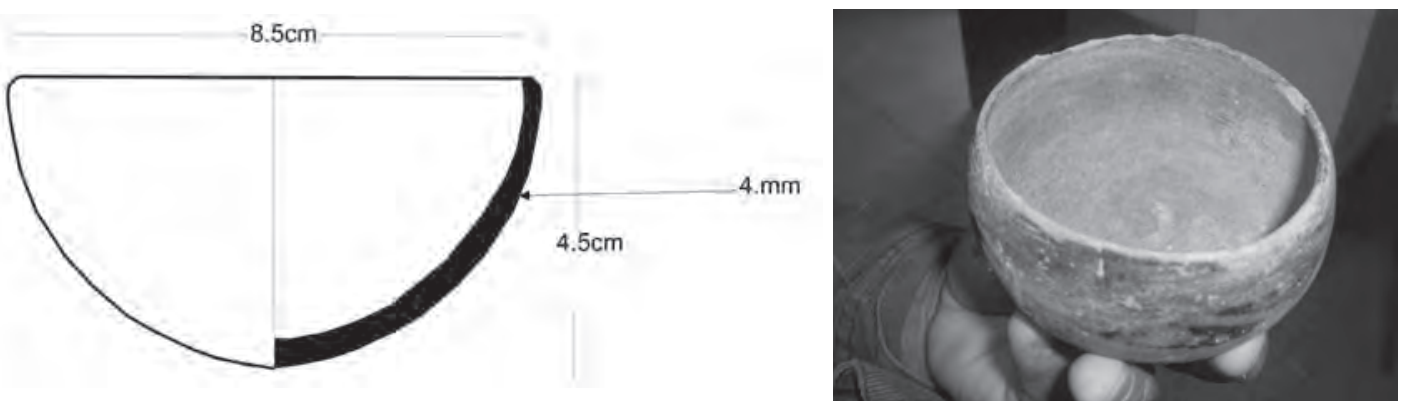

Figura 17. Dibujo y foto de cuenco de estilo Wari Negro con tierra de color rojo en su interior (hallazgo 2). 

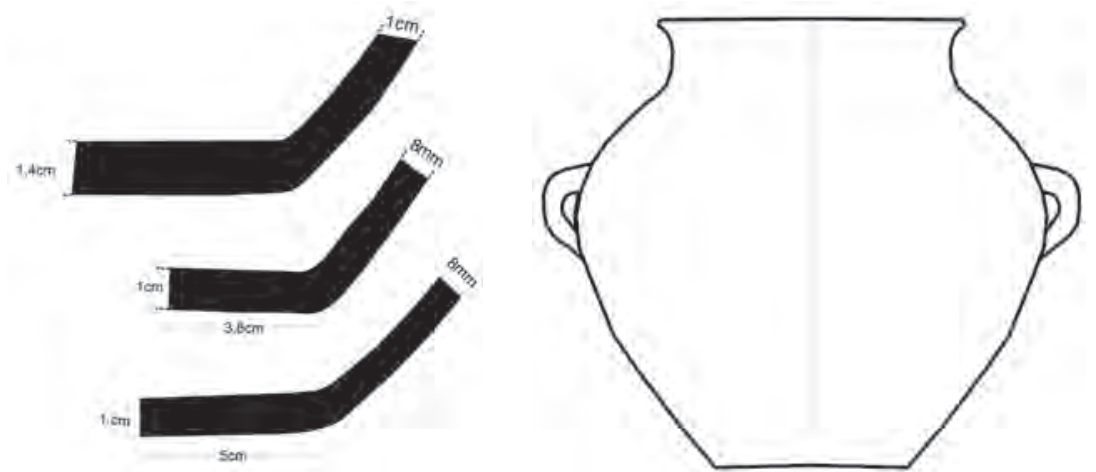

Figura 18. Fragmentos de cántaros según la forma reconstruida.
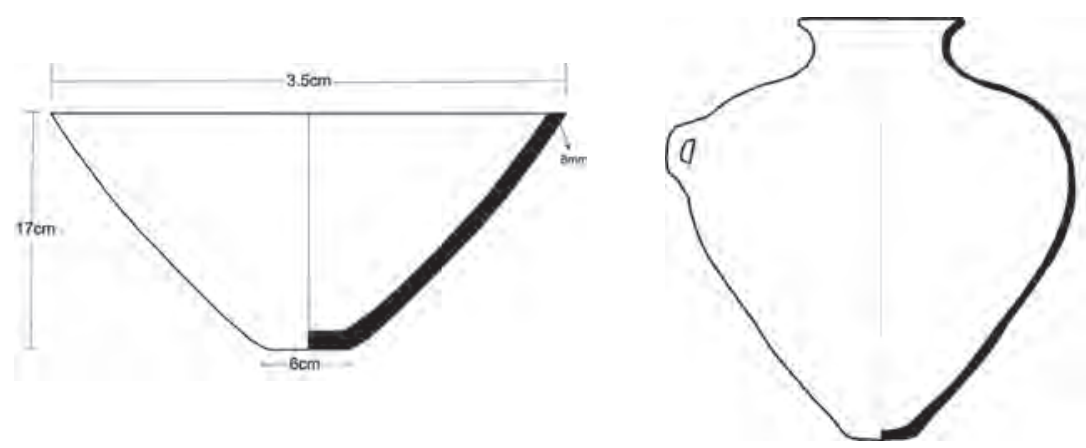

Figura 19. Escudilla y cántaro reconstruido con fragmentos del hallazgo o contexto 2.
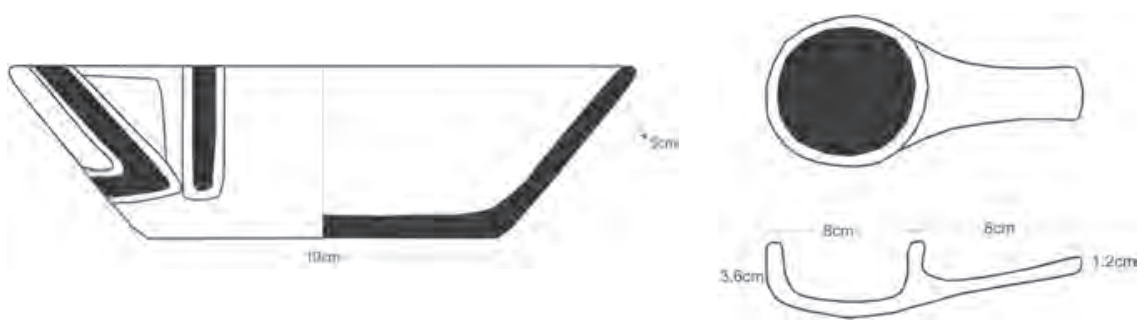

Figura 20. Escudilla y cuchara reconstruidos en base a fragmentos procedentes del contexto 2.
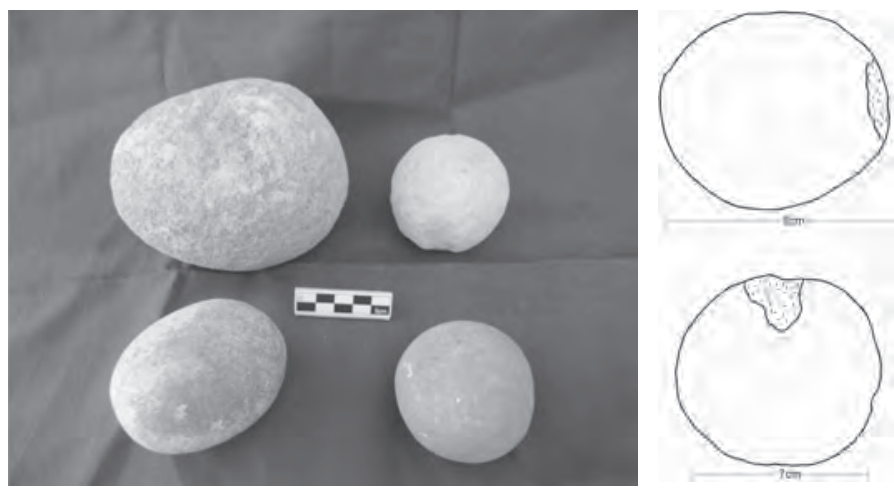

Figura 21. Cantos rodados con desgaste de uso doméstico, contexto 2 


\section{HALLAZGO 3}

Ubicación

Clase de Objeto

Fecha de hallazgo :
: Unidad 3C

Macana de piedra (andesita), procede de la capa de relleno que nivelaba el lado norte de la plaza.

6 de mayo de 2009.

Comentario

: Artefacto prehispánico traído de un asentamiento arqueológico cercano en medio del escombro para rellenar el desnivel de la plaza. La macana se encuentra en buen estado de conservación y corresponde a la época Wari por asociación con fragmentos de cerámica de estilo Huamanga.
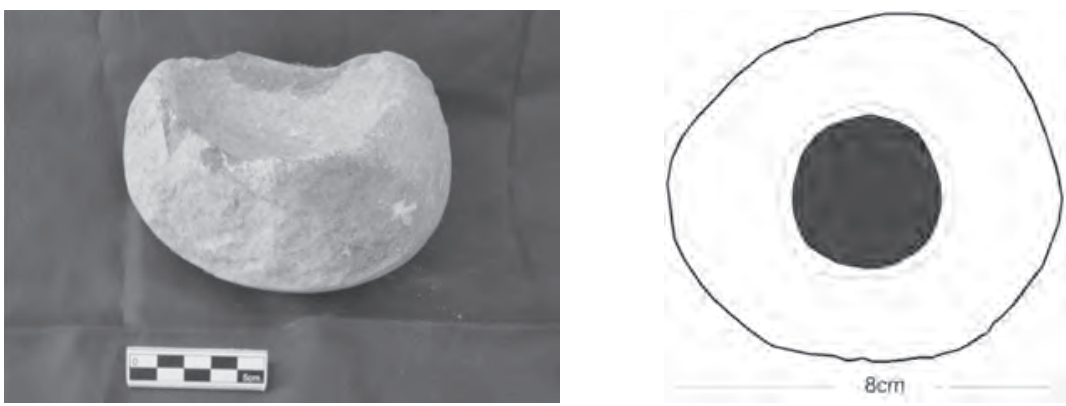

Figura 22. Mortero de piedra o hallazgo 3.

\section{HALLAZGO 4}

Ubicación : Unidad1D.

Clase de contexto : Batan entero de piedra (basalto), con cara activa cóncava producto del desgaste por actividad humana, procede de la capa de material de relleno depositado sobre la capa natural del terreno compuesto por material arcilloso de coloración rojiza. Mide $48 \mathrm{~cm}$ de largo por $8,5 \mathrm{~cm}$ de alto y $3 \mathrm{~cm}$ de profundidad.

Fecha del hallazgo : 5 de mayo de junio de 2009.

Comentario : Se trata sin duda de un objeto que por asociación con los demás hallazgos pertenece a la época Wari solo que su presencia implica la existencia de áreas de actividad vinculados con viviendas domesticas o tallares de producción de cerámica donde los batanes son utilizados para moler las tierras de color o la misma arcilla o material desgrasante.
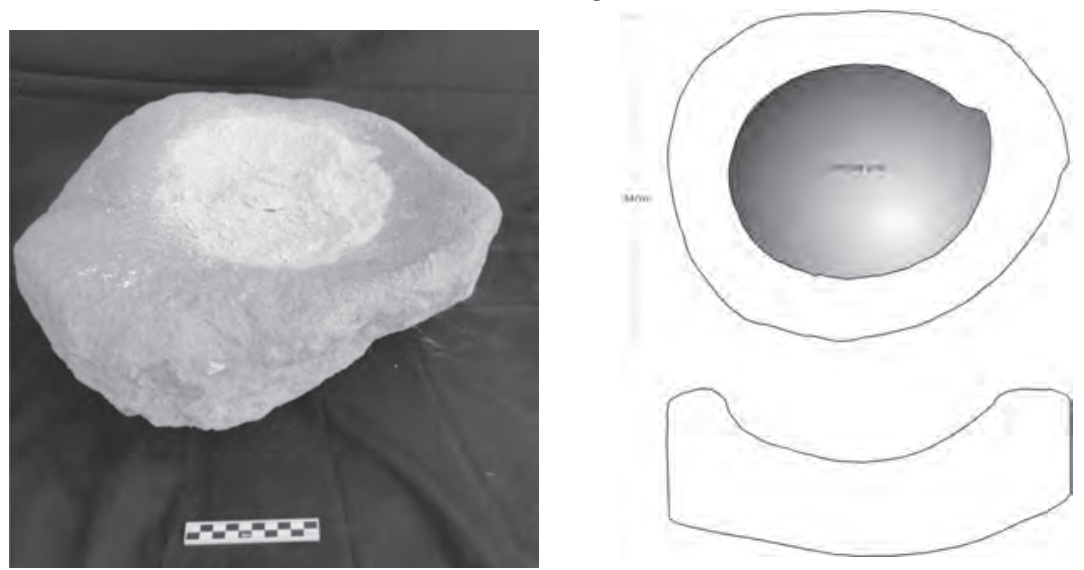

Figura 23. Batan con la parte activa cóncava producto del uso doméstico. 


\section{HALLAZGO 5}

Ubicación : Unidad 3D.

Clase de Hallazgo : Concentración de abundantes fragmentos de cerámica, depositada a manera de basural en el que resaltan diferentes formas y estilos de vasijas de la época Wari. Forma parte de un contexto que se extiende hacia el lado noroeste de la plaza.

Fecha de hallazgo : 5 de junio de 2009.

Comentario : Es probable que de este contexto corresponda a un depósito secundario de desechos de cerámica proveniente de talleres cercanos que formaban parte del asentamiento cuyas estructuras fueron destruidas cuando se efectuaron los trabajos para nivelar el declive de la plaza. El ángulo norte de la plaza es un espacio con un importante contenido cultural como para descifrar el tipo de asentamiento Wari que existió en el área que hoy ocupa la actual plaza de Santa Ana.
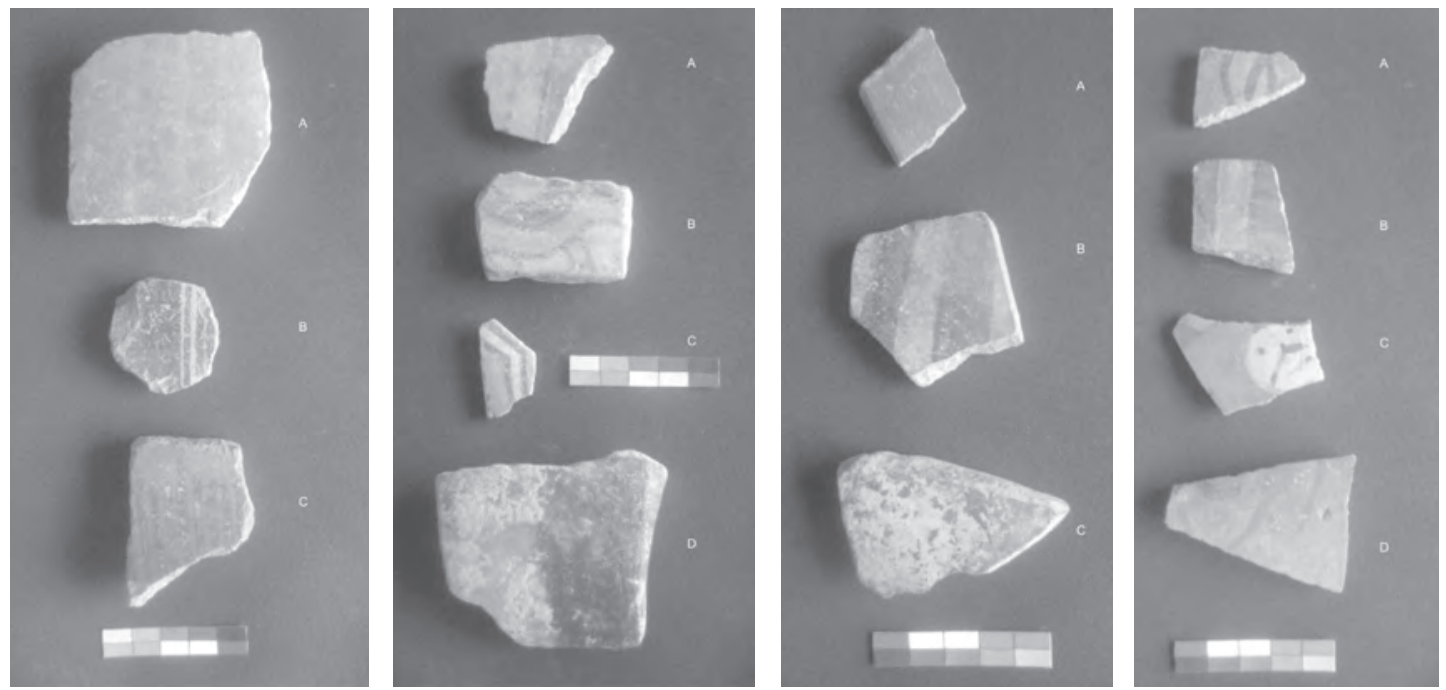

Figura 24. Alisadores de fragmentos de cerámica Huarpa y Wari indicadores de la presencia de talleres de alfareros en el área de la plaza de Santa Ana.

Figura 25. Azada y punta de azadón utilizado tanto en actividades agrícolas como en la extracción de y preparación de arcilla (Hallazgo 5). 


\section{REGISTRO DE CONTEXTOS FUNERARIOS Y CEREMONIALES}

Un conjunto de tumbas como parte de un cementerio Wari fue descubierto de manera circunstancial el 18 de noviembre de 2009 cuando una moto niveladora acondicionaba el terreno para un jardín o área verde en el ángulo sureste de la plaza, el hecho ocurrió cuando el trabajo de monitoreo ya había concluido, por entonces recibida la noticia del Ing. Tele Riveros Agüero Residente de la obra «Construcción, pavimentación de vías, construcción de veredas y tratamiento de la Plaza de Santa Ana», inmediatamente recurrimos al Instituto Nacional de Cultura donde ya habían llegado algunos periodistas de la localidad, en una entrevista con Marcelina Berrocal (encargada de la dirección del INC/RA), optamos por constatar en el propio sitio y efectuar trabajos de rescate para lo cual contamos con la participación voluntaria de varios arqueólogos como Alexander Gallardo Pinco, Edwar Perlacios Flores y los estudiantes Hamilton Paredes Huarcaya, Ivan Galindo Mendieta Edwin Guerreros Ccorahua, Gavy Jayo Alanya y July Mendoza Prado.

Tomando como referencia una de las tumbas destapadas por la maquinaria, cuadriculamos una unidad de 10 x 10 m donde llegamos a registrar siete tumbas con tapas de piedra dispuestas casi al mismo nivel unas cercas de otras señalando que estábamos en un espacio utilizado como cementerio de un poblado Wari que tuvo como núcleo habitacional el ángulo noreste de la plaza, precisamente donde los trabajos de remodelación se han acondicionado al nivel de la superficie original del terreno.

\section{ENTIERRO 1}

Clase de entierro : Tumba en cista de forma circular.

Ubicación tridimensional: Noreste $6,20 \mathrm{~m}$; sureste $16,30 \mathrm{~m}$ por $20 \mathrm{~cm}$ de profundidad con relación al borde del sardinel del actual jardín de la plaza de Santa Ana.

Registro : Edwar Perlacios Flores.

Fecha : San Ana 25 noviembre 2009.

Descripción : Estructura de canto rodado enchapado a los lados verticales de un hoyo de forma cilíndrica excavado bajo el suelo estéril, corresponde a una tumba que tenía como tapa una piedra plana de río, la boca mide $45 \mathrm{~cm}$ de diámetro por 90 $\mathrm{cm}$ de profundidad, contenía tierra suelta con restos de huesos desintegrados por la humedad del terreno formando una capa de unos $25 \mathrm{~cm}$ sobre la base o fondo de la tumba constituida por el mismo suelo estéril. La tumba carecía de elementos culturales asociados.

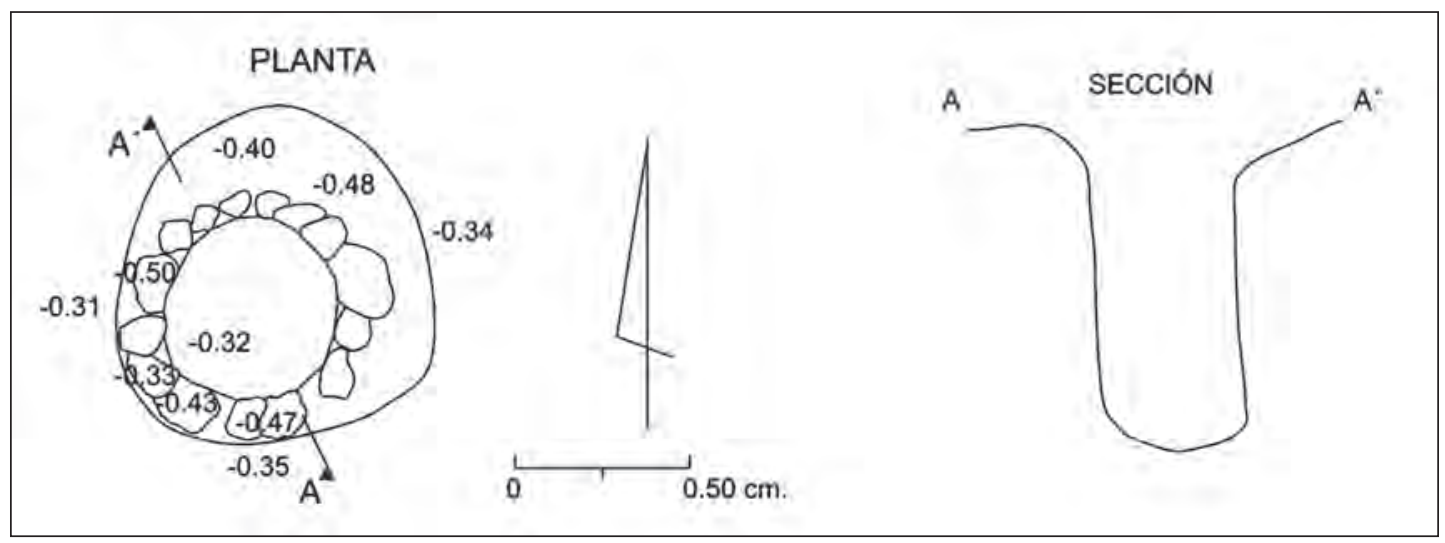

Figura 26. Planta y cortes de del entierro o tumba 1. 


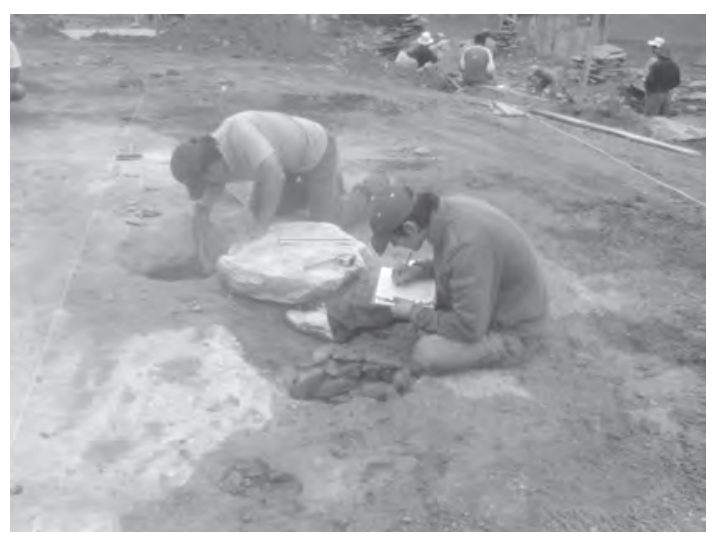

Figura 27. Alexander Gallardo y Edwar Perlacios registrando la estructura de la tumba 1.

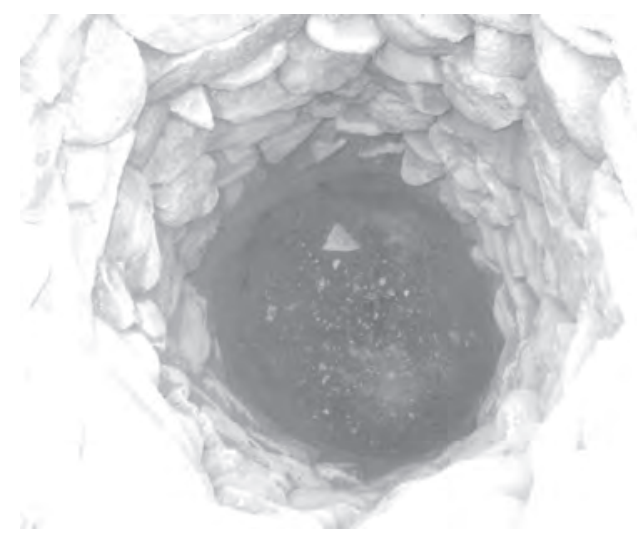

Figura 28. Interior Tumba 1

\section{ENTIERRO 2}

Clase de entierro : Tumba en fosa.

Ubicación tridimensional: Noreste $6,40 \mathrm{~m}$, sureste $17,50 \mathrm{~m}$ por $66 \mathrm{~cm}$ de alto y la boca a $20 \mathrm{~cm}$ bajo el borde del sardinel del jardín o área verde.

Registro : Edwar Perlacios Flores.

Fecha : 25 de noviembre de 2009.

Descripción : : Se trata de una tumba hecha en un hoyo de forma irregular excavada en el suelo estéril sin estructura de piedra la boca tiene entre 60 a $80 \mathrm{~cm}$ de diámetro por $66 \mathrm{~cm}$ de profundidad, estaba cubierta de tierra suelta con restos óseos humanos totalmente consumidos por la humedad. Se ubica a menos de un metro al noreste de la tumba anterior.

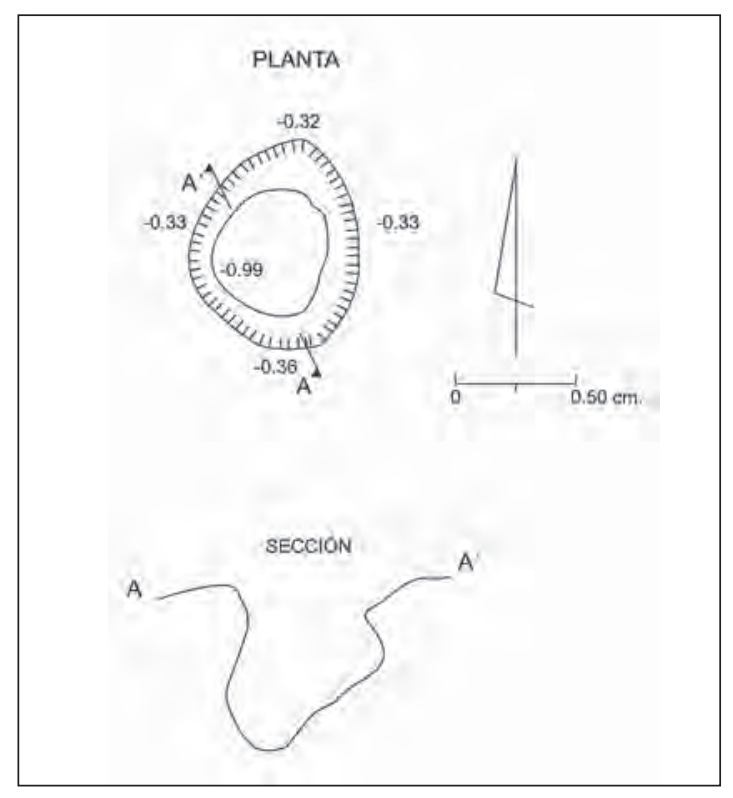

Figura 29. Planta y cortes de la tumba 2

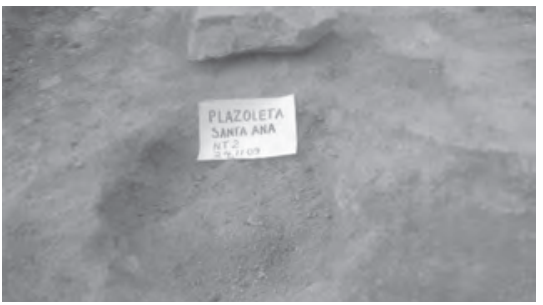

Figura 30. Superficie de la fosa del entierro individual

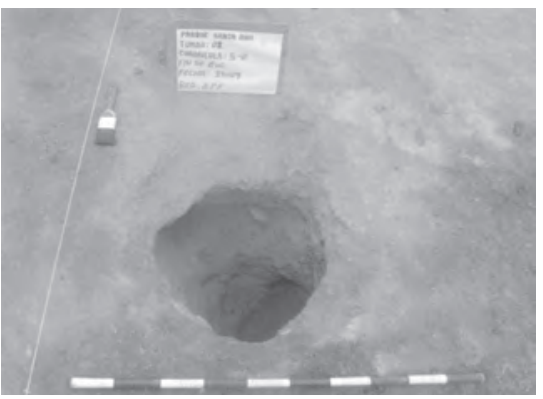

Figura 31. Fosa del entierro 2. 


\section{ENTIERRO 3}

Ubicación tridimensional: Noreste 6,70 m, sureste 21,90 m y $22 \mathrm{~cm}$ bajo el borde del sardinel

Registro : : Alexander Gallardo Pinco.

Fecha : Santa Ana 25 de noviembre de 2009.

Descripción : : Tumba hecha en un hoyo en forma de «8» separado por una laja parada que la divide en dos cuerpos excavados en el suelo estéril sin pared de piedra, no tenía tapa y estaba cubierta de tierra suelta de color amarillenta con partículas de huesos humanos y asociados con un canto rodado colocado en el lado suroeste sobre la base o suelo estéril del hoyo del lado norte, mientras que en el centro del hoyo mayor o el lado sur había un cuenco de estilo Huamanga, depositado con la boca rozando la base del hoyo, corresponde a ofrendas de entierros humanos desintegrados por la humedad.

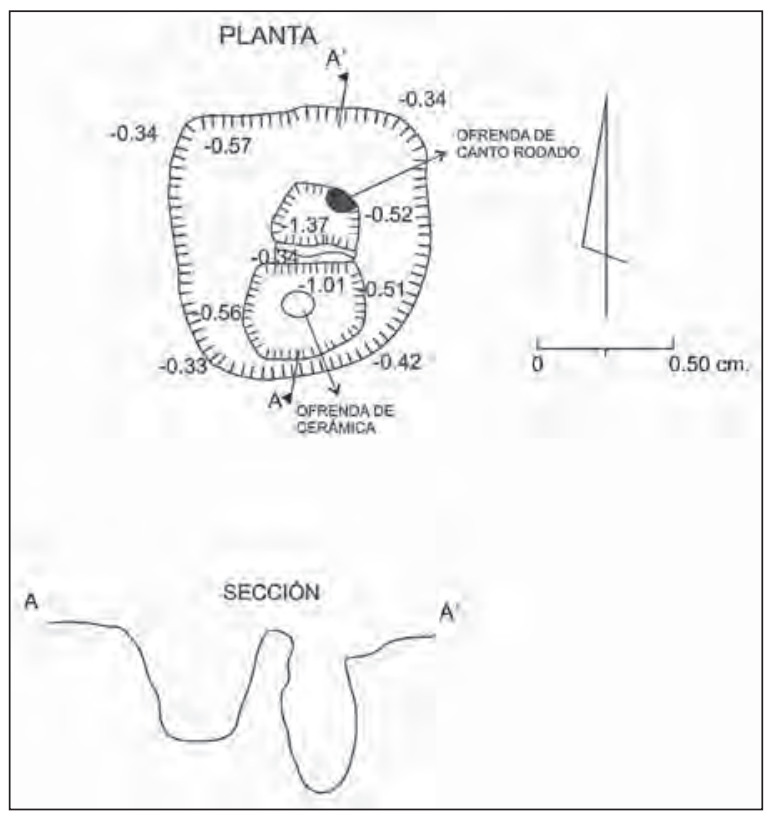

Figura 32. Planta y cortes de la tumba 3.

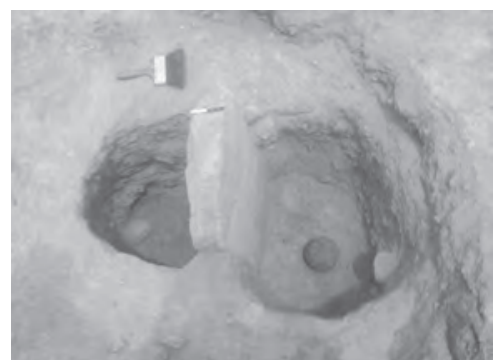

Figura 33. Fosa con división para entierro individual con ofrendas.

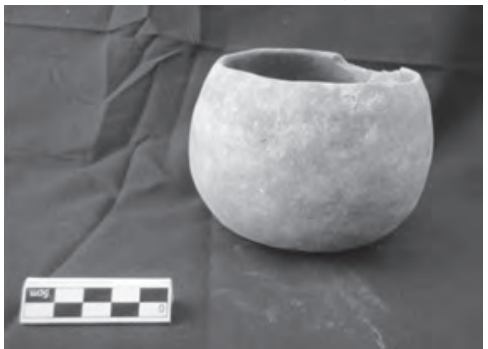

Figura 34. Detalle de cuenco wari, estilo local.

\section{ENTIERRO 4}

Clase de entierro : Tumba en cista.

Ubicación tridimensional: Sureste 10,40 m; noreste 4,20 m y $15 \mathrm{~cm}$ bajo el sardinal actual del jardín de la plaza.

Registro : Edwar Perlacios Flores.

Fecha : Santa Ana 08 de diciembre de 2009.

Descripción : Estructura de canto rodado enchapado a un hoyo de forma cilíndrica excavado bajo el suelo estéril y tapado con dos piedras planas y alargadas de río. La tumba tiene boca de $50 \mathrm{~cm}$ de diámetro por 96 de profundidad y junto al borde noreste había dos tupos de cobre (uno doblado y el otro normal) depositados como posibles ofrendas después de haber sellado la tumba, el interior contenía tierra con restos óseos desintegrados por la humedad en medio de lo cual había un tupo pequeño de cabeza rectangular. 


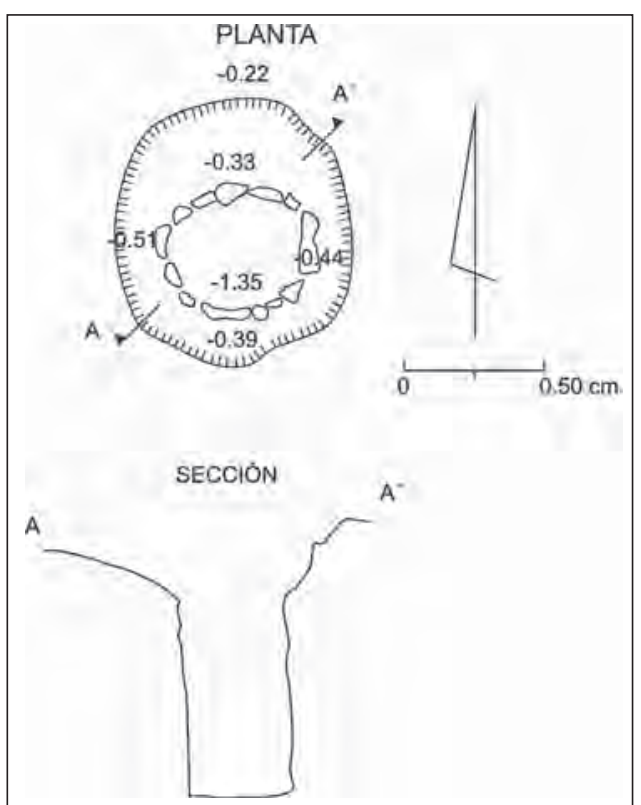

Figura 35. Planta y cortes de la tumba 4.

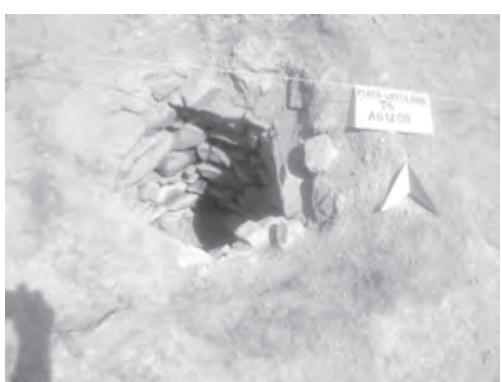

Figura 36. Estructura de la tumba 4.

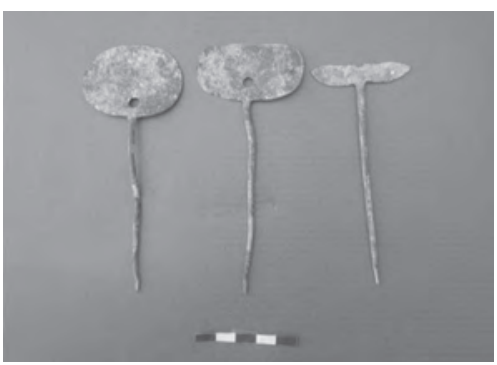

Figura 37. Tupos de la tumba 4.

\section{ENTIERRO 5}

Clase de entierro : Fragmentos de cerámica

Ubicación tridimensional: Sureste 10, $40 \mathrm{~m}$; noreste 4,20 m y $15 \mathrm{~cm}$ bajo el sardinel del jardín de la plaza.

Registro : Edwar Perlacios Flores.

Descripción : Estructura de piedra enchapada a un hoyo excavado en suelo estéril, tiene forma cilíndrica la boca mide $70 \mathrm{~cm}$ de ancho y la base de $66 \mathrm{~cm}$, por $90 \mathrm{~cm}$ de profundidad, contenía tierra con restos óseos totalmente descompuestos que

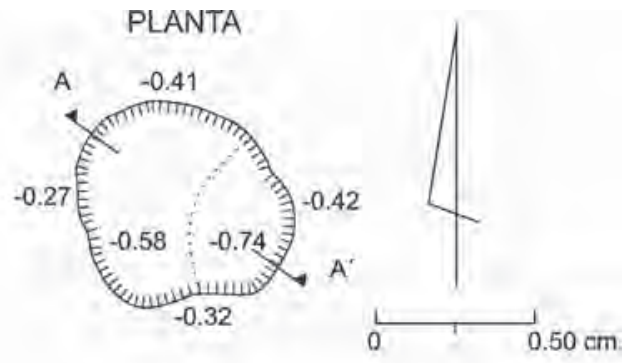

SECCIÓN

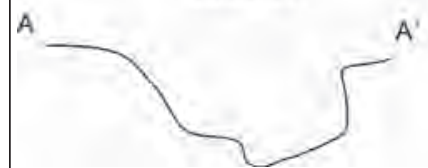

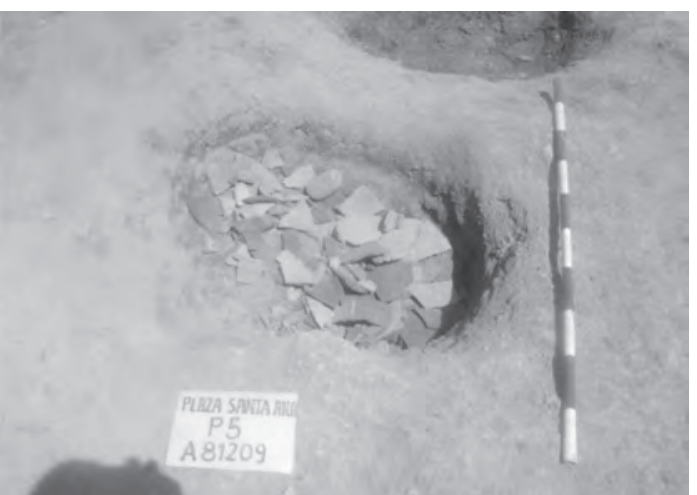

Figura 39. Contenido entierro 5.

Figura 38. Planta y cortes del entierro 5. 
rellenaba la parte inferior de la profundidad de la tumba, sin cerámica y artefactos líticos ni tupos asociados.

\section{ENTIERRO 6}

Clase de entierro : Tumba en cista circular.

Ubicación tridimensional: Sureste $10,4 \mathrm{~m}$; noreste $4,20 \mathrm{~m}$ y $15 \mathrm{~cm}$ bajo el mismo sardinel actual del jardín de la plaza.

\section{Registro : Gavy Jayo Alanya.}

Descripción : Estructura de piedra enchapada a un hoyo excavado en suelo estéril, tiene forma cilíndrica la boca mide $70 \mathrm{~cm}$ de ancho y la base de $66 \mathrm{~cm}$, por $90 \mathrm{~cm}$ de profundidad, contenía tierra acumulada con restos óseos descompuestos que cubrían la parte inferior de la tumba, contenía 2 platos de cerámica Wari, de estilo Huamanga o Santa Ana.

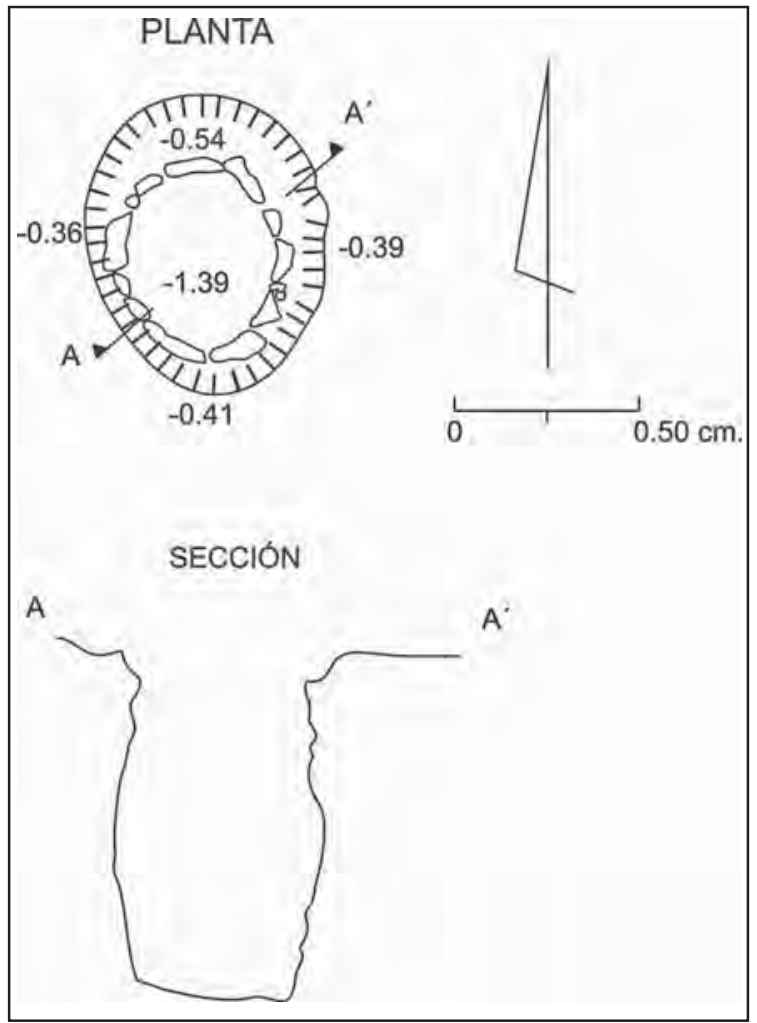

Figura 40. Planta y cortes de tumba 5 o entierro 6

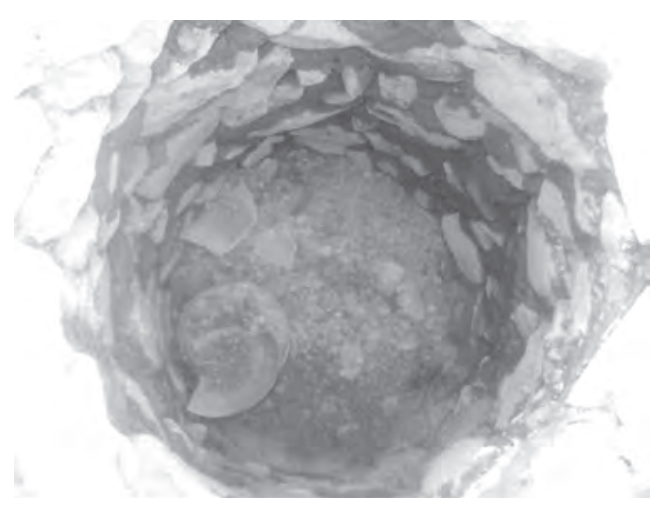

Figura 41. Ofrendas asociadas a la tumba 5.

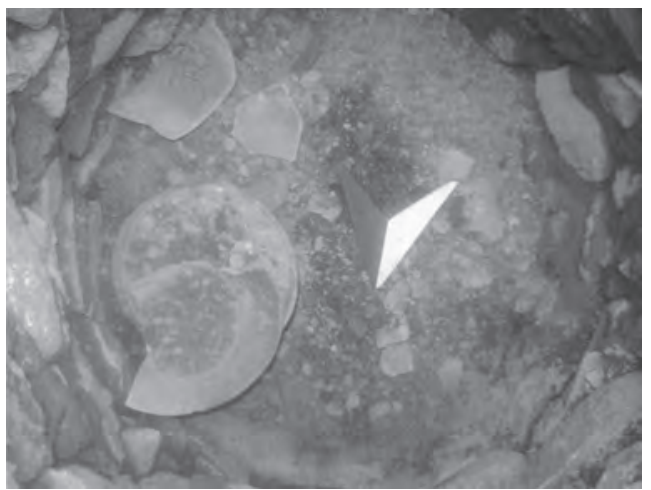

Figura 42. Detalle de las ofrendas.

\section{ENTIERRO 7}

Ubicación tridimensional: Sureste 10,4 m; noreste 4,20 m y $15 \mathrm{~cm}$ bajo el mismo sardinel actual del jardín de la plaza.

Registro : : Hamiltón Paredes Huarcaya.

Descripción : Estructura de piedra enchapada a un hoyo excavado bajo el suelo estéril, tiene forma cilíndrica la boca mide $70 \mathrm{~cm}$ de ancho y la base de $66 \mathrm{~cm}$, por $90 \mathrm{~cm}$ de profundidad, contenía tierra con restos óseos descompuestos y acumulados sobre la base de la tumba, carecía de objetos arqueológicos asociados. 

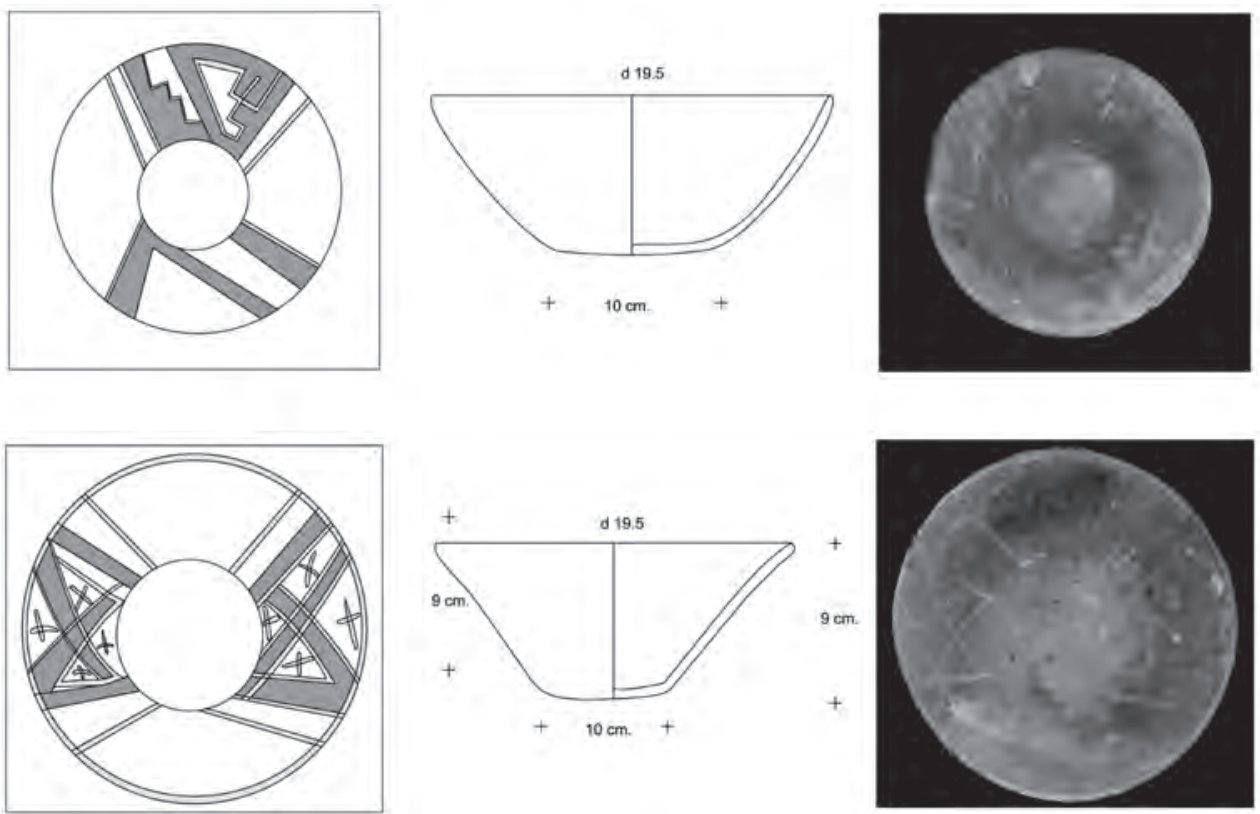

Figura 43. Dibujos de planta, secciones y fotos de las escudillas Wari de estilo local Santa Ana (Huamanga) procedente de la tumba 5.

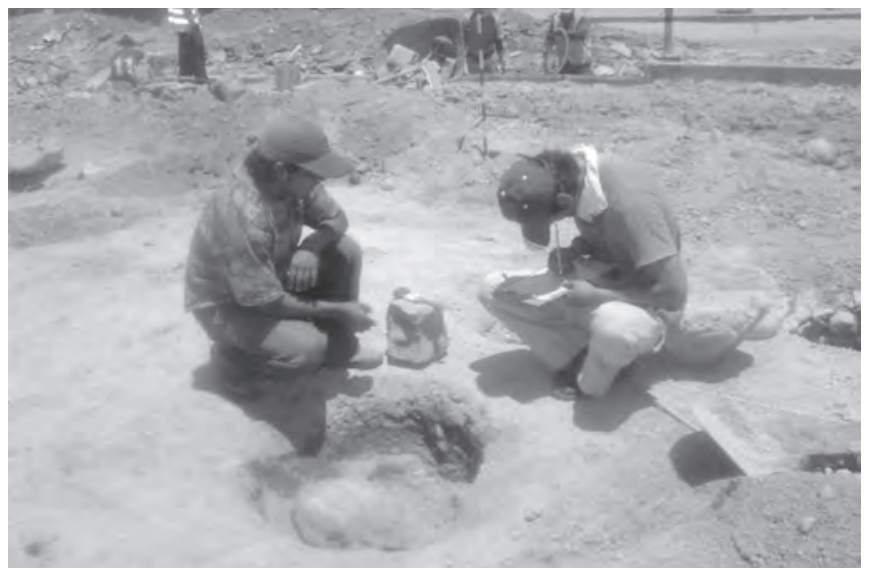

Figura 44. Planta y cortes del entierro 7 o tumba 6.

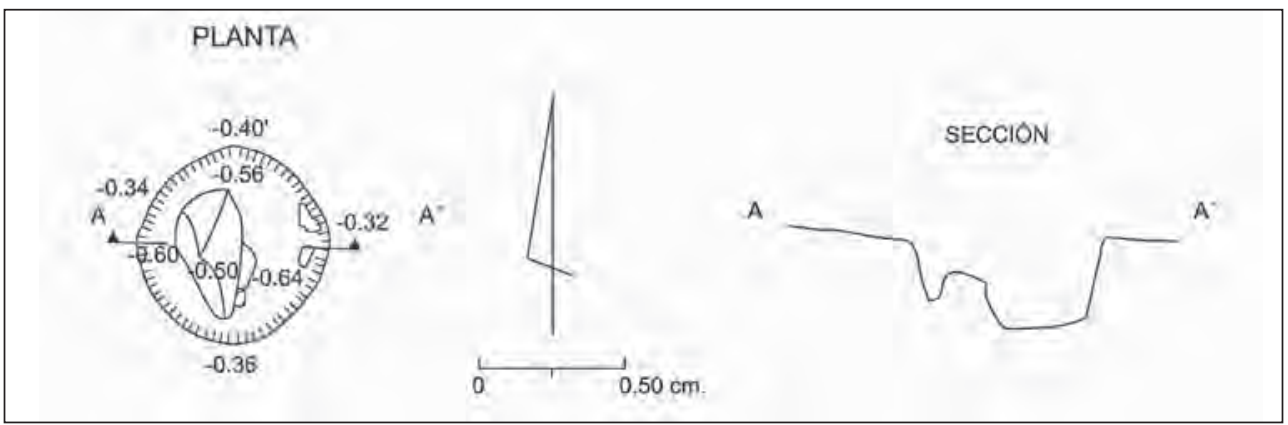

Figura 45. Registro gráfico del entierro 7. 


\section{ETNOGRAFÍA TEXTIL Y ALFARERA}

En la actual ciudad de Ayacucho, la comunidad o barrio de Santa Ana es conocido fundamentalmente por la producción textil de tejido a pedal introducido por los españoles desde el siglo XVI, de lo que se han elaborado diferentes trabajos de investigación (Quispe 1983; Altez 1981), de las fiestas tradicionales (García 1971) de la formación como comunidad campesina (Condori 1982), así como de la construcción de la templo colonial más antiguo o primera catedral (Alberdi 2010).

Otra de las expresiones etnográficas que se mantiene vigente en Ayacucho y que se puede contrastar con la información arqueológica encontrada en el mismo Santa Ana es la producción de cerámica heredada de abuelos, hijos y nietos, para lo cual tuvimos la oportunidad de conversar con la familia del don Leoncio Tineo (+) distinguido ceramista que la heredó de su madre doña María Ochoa, el arte de modelar en barro con el uso del color de la arcilla y los tonos rojizos, y de su padre las formas escultóricas de tamaño grande.

Don Leoncio, ha dejado una enorme cantidad de trabajos relacionados con la imaginería religiosa de ángeles, vírgenes, nacimientos, entre otras, así como las costumbres de su tierra natal. Muchos de ellos llevan una historia escondida, otros están relacionados a la agricultura y a la vida diaria del campesino.

La tradición alfarera de don Leoncio continua en sus hijas Julia, Rosalía y en su nieto, elaborando piezas de original belleza. Las obras de don Leoncio se encuentran en museos en el Perú y en el extranjero y tal como comenta don Alejandro Gallardo (maestro en arte textil) la obra de la familia Tineo de los últimos tiempos no ha permanecido ajena a su realidad social, de la que ha incorporado temas de los tristes sucesos que han marcado las dos últimas décadas del siglo xx y su impacto en la vida cotidiana de la gente del barrio de Santa Ana.

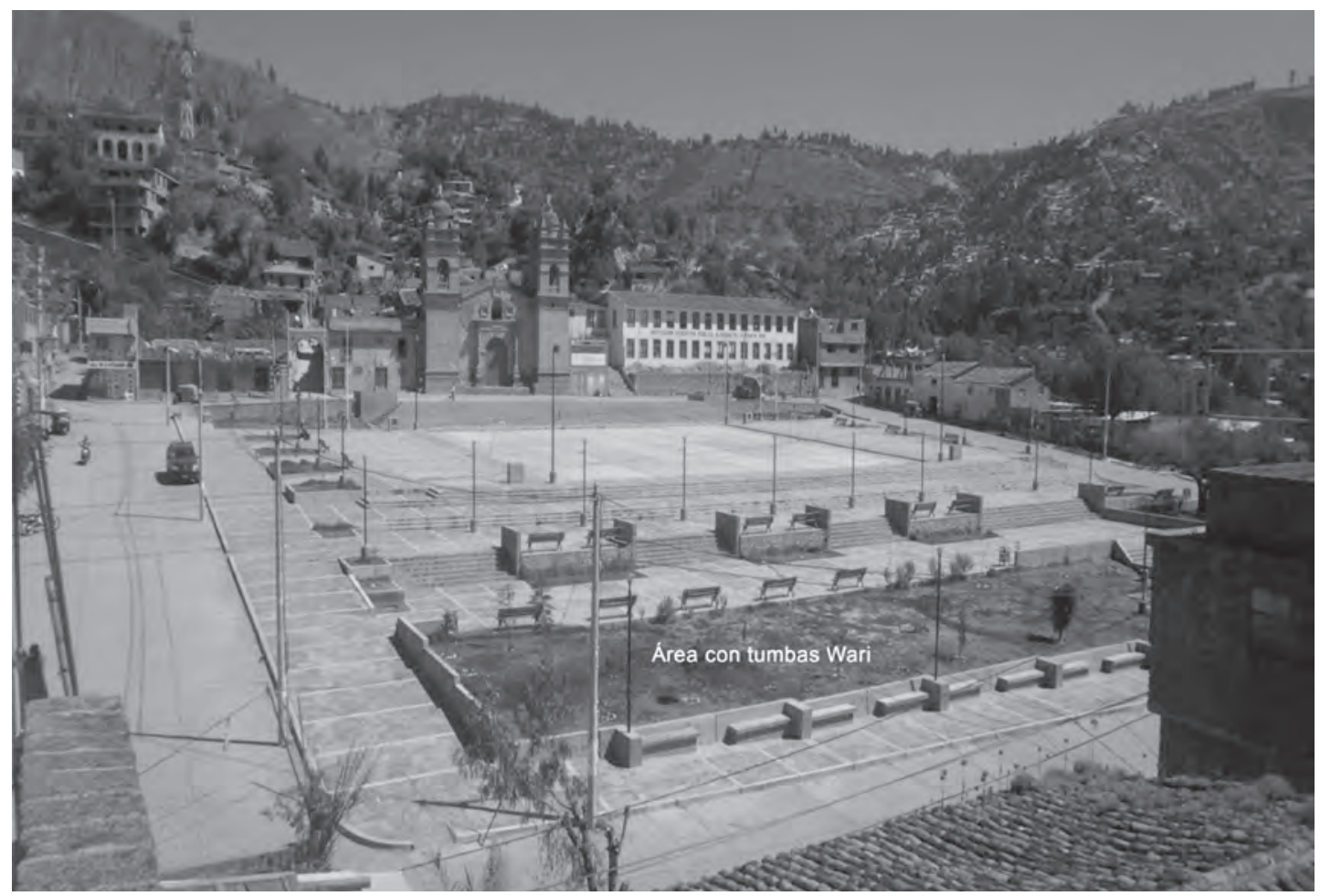

Figura 46. Plaza de Santa Ana después de la remodelación (2010). 


\section{BREVE DISCUSIÓN}

Si bien el asentamiento arqueológico de Conchopata es catalogado como el principal centro de producción de cerámica de la época Wari, Pozzi Escot (1982; 1985); Pozzi-Escot y Córdova (1983); Isbell (1985, 2009); Pérez (1998), Pérez y Ochatoma (1998); Ochatoma (2007), etc.), las investigaciones efectuadas en las tres ultimas décadas han dado a conocer que en las inmediaciones de Conchopata, en la misma actual ciudad de Ayacucho existen otros asentamientos de menor jerarquía con restos de producción alfarera.

Uno de los sitios reportados desde fines de la década de 1980 es Aqo Wayqo, excavado por José Ochatoma (1989), donde Mariscoth Alarcón (1990) que participó en las excavaciones y analizó parte del material cultural asociado, sostiene que los artefactos líticos conocidos como asadas tuvieron múltiples usos, desde labores agrícolas hasta el empleo en el proceso de la obtención, preparación y elaboración de las vasijas básicamente ollas y cantaros grandes, los mismos que debieron ser llevados a la capital Wari como una especie de aporte o contribución tributaria, razón por la que denomina los olleros de Aqo Wayqo, dicho trabajo ofrece una interesante clasificación de la cerámica Wari de estilo Huamanga. En 1991 cuando participábamos en las excavaciones promovidas por Marcelina Berrocal (1991) en la colina de Muyo Orqo, ubicada a menos de $1 \mathrm{~km}$ al norte de Aqo Wayqo, en uno de los recintos y sobre lo que pudo haber sido una banqueta dispuesta a manera de mesa de trabajo, encontramos varios fragmentos de cerámica, dentro de estos un plato casi íntegro de estilo Cajamarca III con restos de tierra de color rojo en su interior a semejanza de los recipientes que utilizan los actuales alfareros de Quinua para decorar las vasijas. Esta evidencia advertía que estábamos cerca de áreas de trabajo o tallares de producción de cerámica local, trece años después cuando el suscrito (Pérez 2003; 2004) realizó excavaciones de emergencia en un área de $300 \mathrm{~m}^{2}$ tuvimos la oportunidad de descubrir más 20 recintos cerrados conectados a un patio ceremonial y probable plaza, uno de los recintos contenía un fogón junto a fragmentos de vasijas rotas intencionalmente por los propios ocupantes antes del abandono del sitio, dentro de estos algunos alisadores y pulidores dispersos sobre el un piso compacto quemado por la ocupación doméstica y artesanal, indudablemente estábamos frente a un taller cuya forma del recinto es parecido a uno de los talleres excavados en 1993 en Conchopata (Pérez 1998: 129); (Ochatoma 2007: 160-161).

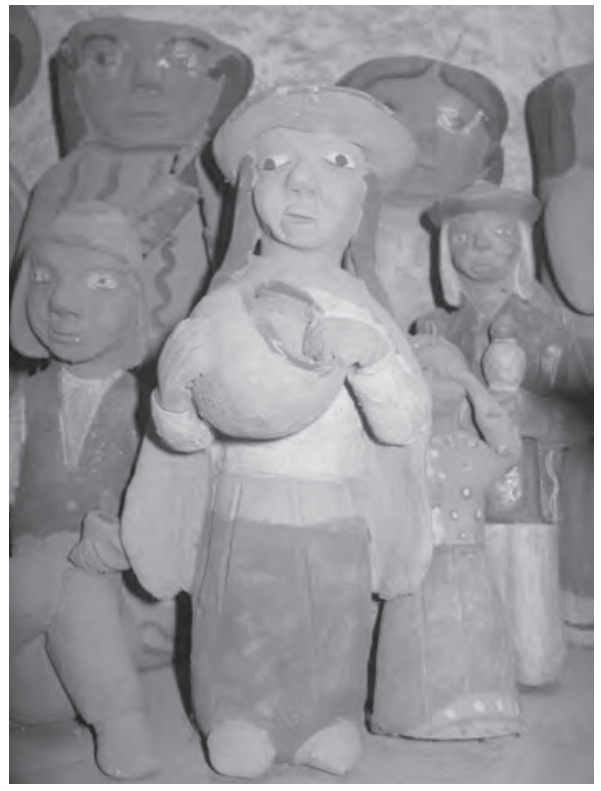

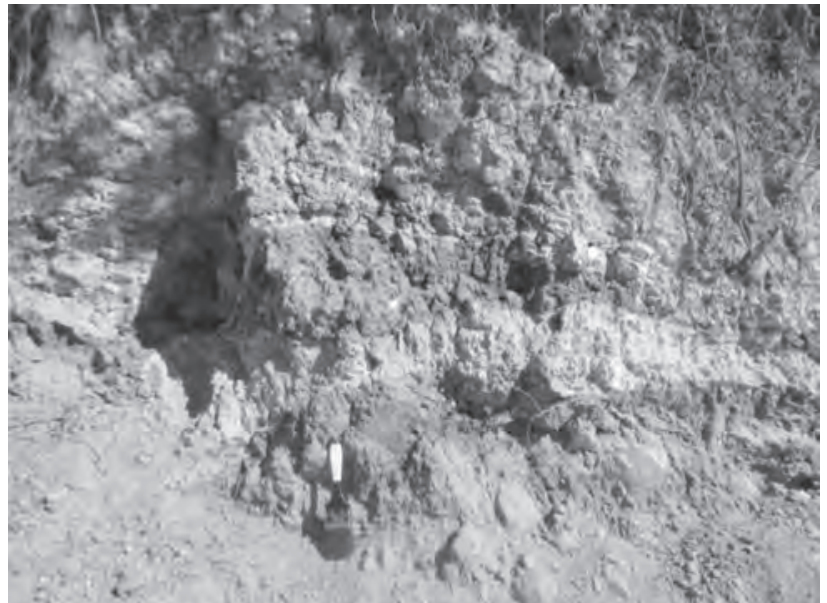

Figura 48. Canteras de arcilla en el área de la misma plaza de Santa Ana.

Figura 47. Producción de cerámica de don Leoncio Tineo. 
En el valle de Huamanga, aparte de volver a visitar sitios arqueológicos prospectados en décadas anteriores, se han explorado nuevos sitios en cuyo reconocimiento y estudio se han logrado documentar a nivel de superficie de áreas disturbadas del terreno, diferentes artefactos entre alisadores, pulidores, asadas, etc. vinculados con la cadena de producción de cerámica.

Estos sitios ocupan la periferia noroeste y sureste dispuestos entre $1 \mathrm{a} 2 \mathrm{~km}$ de distancia con relación al Conchopata, hecho que conlleva a entender que la fabricación de la cerámica local no solo se manufacturaba en poblados urbanos sino también en poblados rurales, y lo que falta indaga si la producción de estos poblados menores fueron controlados por el Estado imperial o fue solo para satisfacer la demanda de la población local e intercambios con los poblados aledaños.

\section{CONCLUSIONES E HIPÓTESIS}

La plaza Santa Ana (Jerusalén) ocupa un lugar con restos culturales de una antigua ocupación prehispánica que fue destruida en la época colonial para la creación del actual barrio o Qanan Parroquia.

La estratigrafía cultural asociada corresponde a material de relleno nivelado en diferentes oportunidades como parte de remodelaciones y mejoramientos de la plaza desde la época colonial.

Los materiales arqueológicos recuperados durante el los trabajos de monitoreo corresponden a las épocas Huarpa y Wari dispuestos en distintas capas de tierra removida que nivelaba el declive noroeste que da a las calles Mariscal Cáceres y Santa Cecilia.

El terreno donde ubicamos el hallazgo 5 (cuadrante 3D), frente a la vivienda de la familia Gálvez, forma parte de un contexto con abundante fragmentos de cerámica y artefactos líticos depositado a manera de basural, parte del cual queda como testigo para posteriores investigaciones. Las evidencias se proyectan hacia el lado este de la plaza, bajo una capa de relleno de tierra que nivela la superficie de la antigua plaza colonial.

Los entierros encontrados en el lado noreste de la plaza forman parte de un probable cementerio Wari con vestigios que aun queda en el subsuelo del espacio dejado como jardín.

En base a los restos culturales encontrados, sostenemos que el asentamiento de la época Wari ocupaba la cima y laderas superiores de una colina, donde pudo haber existido la estructura a un templo ceremonial, destruido y nivelado para trazar la nueva traza urbana de tipo occidental que caracteriza de manera particular al tradicional barrio de Santa Ana. Por otro lado el hallazgo de alisadores, vasija con tierra de color y arcilla indican la producción de cerámica local o de estilo Santa Ana.

\section{Agradecimientos}

A Marleni Marisctoh Alarcón Guerrero, por el habernos contactado con la Municipalidad Provincial de Huamanga, encargada de la obra: «Construcción, pavimentación de vías, construcción de veredas, y tratamiento de la plaza Santa Ana, distrito de Ayacucho, provincia de Huamanga-Ayacucho», logrando de esta manera dirigir las labores de monitoreo arqueológico en el 2009, lo cual culminó con el rescate del conjunto de entierros Wari en el lado noreste de la plaza gracias a la oportuna participación de Marcelina Berrocal Avilés, encargada de la Dirección del Instituto Nacional de Cultura, Ayacucho. Angélica Canchari Castro y Edwar Perlacios Flores, no solo apoyaron en el registro de datos sino también se encargaron de elaborar los dibujos que ilustran la presente publicación; Alexander Gallardo Pinco, Hamilton Paredes Huarcaya, Edwin Guerrero Cuadros, Irvin Galindo Mendieta, Gavy Jayo Alanya y July Mendoza Prado participaron voluntariamente en el rescate y registro de evidencias, y al maestro de tejido en telar a pedal, Sr. Alejandro Gallardo por compartir y entender nuestra inquietud en la búsqueda de información etnográfica, a todos ellos mi más sincero y profundo agradecimiento. 


\section{BiBLIOGRAFÍA}

ALTEZ, Zenaida

1981 La artesanía textil en la comunidad campesina de Andamarca. Tesis para optar el título de Asistente Social, Universidad Nacional de San Cristóbal de Huamanga (UNSCH).

ALIAGA, Alajendro y Wilfredo ZEVALLOS

1977 Ayacucho 1900-1950. Desarrollo económico social. Trabajo de Investigación PPAN-502. UNSCH.

ALBERTI, Alfredo

2010 «Civitas Guamangensis: Los hombres, espacios y solares de la villa de San Juan de la Frontera de Huamanga (1540-1547)». Runa Yachachiy, Revista electrónica Virtual, Berlín, Alemania.

ALARCÓN, Marlene

1990 Olleros de la época Wari. Informe de práctica preprofesional, Facultad de Ciencias de Sociales, UNSCH.

BANNETT, Wendel C.

1953 Excavations at Wari, Ayacucho: Peru. Yale University Publications in Anthropology 59. New Haven.

BENAVIDES, Mario

1976 Yacimientos arqueológicos de Ayacucho. Ayacucho: UNSCH.

BERROCAL, Marcelina

1991 Estudio arqueológico en Muyo Orqo, Ayacucho. Informe de práctica Pre-profesional, Facultad de Ciencias Sociales, UNSCH.

BINFORD, Lewis T.

1998 En busca del pasado. Barcelona: Crítica Grijalfo Mondadori .S. A.

CIEZA DE LEÓN, Pedro

1995 [1550] La crónica del Perú. Lima: Pontificia Universidad Católica del Perú (PUCP).

CONDORI, Carlos

1982 Organización Comunal en barriadas de Ayacucho. Informe final de Seminario de Investigación, Programa Académico de Antropología, UNSCH.

\section{CABRERA, Martha}

1991 Investigaciones arqueológicas en Waychaupampa, Ayacucho. Informe de prácticas prerofesionales, Facultad de Ciencias Sociales, UNSCH.

GONZÁLES, Enrique

1966 Investigaciones arqueológicas en Ñawimpukio. Ayacucho: UNSCH.

1972 «Exploraciones en Ñawimpukio, Ayacucho». Arqueología y Sociedad 7-8: 30-46. Lima: Universidad Nacional Mayor de San Marcos (UNMSM).

GONZÁLES, Enrique; Lorenzo HUERTAS y Fermín RIVERA

1980 Estudios históricos de la casa Olano Ayacucho. Dirección Universitaria de Investigaciones, UNSCH.

GONZÁLES, Enrique, Yuri GUTIÉRREZ y Jaime URRUTIA

1995 La ciudad de Huamanga espacio historia y cultura. 1ra. edición. UNSCH, Concejo Provincial de Huamanga y Centro Peruano de Estudios Sociales. Ayacucho: AIDI de Arteta S.A.

GONZÁLEZ, Enrique; Jaime URRUTIA y Jorge LÉVANO

1997 Ayacucho, San Juan de la Frontera de Huamanga. Colección Arte y Tesoros del Perú, Lima: BCP, Ausonia S.A.

GARCÍA, Rubén

1971 El Cargo Religioso en el barrio de Santa Ana. Informe de prácticas preprofesionales, Facultad de Ciencias sociales, UNSCH. 


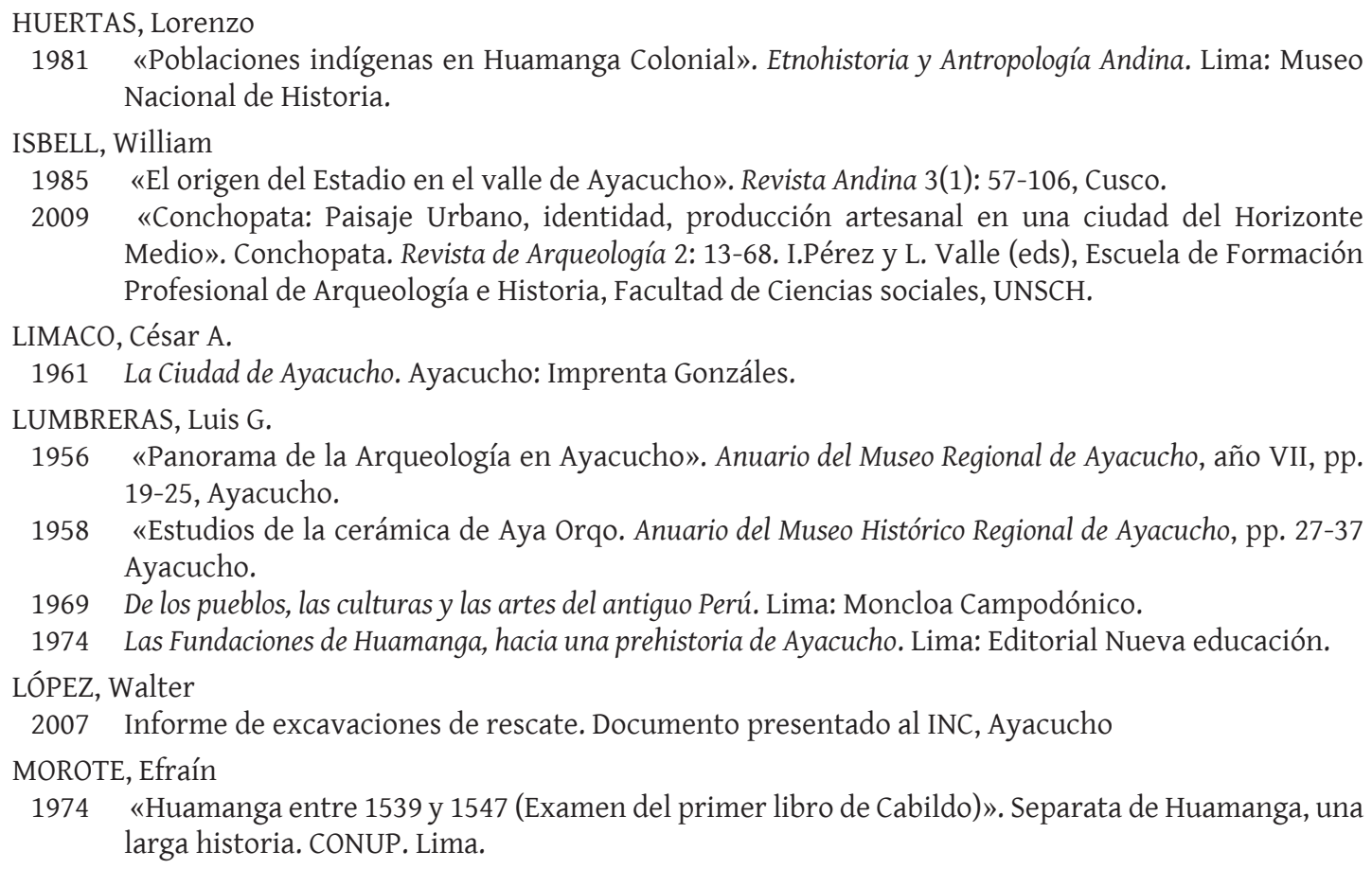

MANCILLA, Raúl

1987 «Apuntes para el estudio de la Arquitectura religiosa del templo de Santa Ana en Ayacucho». Cal y Canto. Pp. 15-19.Revista de circulación de periodistas de turismo de Ayacucho.

MACHACA, Gudelia

1997 Secuencia Cultura y nuevas evidencias de urbanismo en Ñawimpuquio, Ayacucho. Trabajo de investigación, Facultad de Ciencias Sociales, UNSCH.

MACNEISH, R.; A. GARCÍA, L.G. LUMBRERAS, R. VIERRA y A. NELKEN-TERNER

1981 Prehistory of the Ayacucho Basin, Peru. Volume II Excavations and Chronology. Ann Arbor: University of Michigan Press.

MANCILLA, Raúl

2008 Iraqata: sitio de la época Formativa en Ayacucho. Tesis de Licenciatura, UNSCH.

OCHATOMA, José

1989 Aqowayqo: Un poblado rural de la época Wari. Lima: CONCYTEC.

1992 «Acerca del Formativo en ayacucho». En: D. Bonavia (ed.) Estudios de Arqueología Peruana: 193-214. Lima: FONCIENCIAS.

1985 Jarqampata de Huamanga Investigaciones arqueológicas en un yacimiento correspondiente al Horizonte Temprano. Informe para optar el grado de bachiller en Arqueología, UNSCH.

2007 Alfareros del imperio Huari: Vida Cotidiana y áreas de actividad en Conchopata. UNSCH. Lima: Cano Asociados SAC. Lima.

POZZI-ESCOT, Denise

1982 Excavaciones en Conchopata. Informe presentado al Instituto Nacional de cultura. Ayacucho.

1985 «Conchopata un poblado de especialistas durante el Horizonte Medio». Boletín del Instituto Frances de Estudios Andinos 14 (3-4): 115-129. Lima

2009 «Conchopata una comunidad de ceramistas». Conchopata, revista de Arqueología 2: 57-78. I. Pérez y L. Valle (eds), Escuela de Formación Profesional de Arqueología e Historia, Facultad de Ciencias sociales, UNSCH. 
POZZI-ESCOT, Denise y Elsa CÓRDOVA

1983 «Los moldes de cerámica de Conchopata». Revista del Instituto de Investigaciones 1: 15-31. Departamento de Ciencias Histórico-Sociales, UNSCH.

PÉREZ, Ismael

1998 «Excavación y definición de un taller de alfareros Huari en Conchopata». Conchopata, Revista de Arqueología 1: 93-137. Oficina de Investigación, Facultad de Ciencias Sociales, UNSCH.

2003 Informe final de excavaciones de emergencia en Muyo Orqo. INC.

2004 «Indicadores de actividades alfareras en Muyo Orqo, Ayacucho». Investigaciones en Ciencias Sociales 2: 47-74.

2013 «Asentamientos periféricos del centro urbano de Conchopata, Ayacucho». Arqueología y Sociedad 25: 143-168, Lima: UNMSM.

PÉREZ, Ismael y José OCHATOMA

1998 «Viviendas, talleres y hornos de producción alfarera Huari en Conchopata». Conchopata, Revista de Arqueología 1: 72-92. Oficina de Investigación, Facultad de Ciencias Sociales, UNSCH.

QUISPE, Leoncio

1993 La producción textil en la comunidad de Santa Ana. Informe de prácticas Pre-Profesionales, Facultad de Ciencias Sociales, UNSCH.

RUIZ, José

1924 Monografía Histórica geográfica del departamento de Ayacucho. Lima: Imprenta Torres Aguirre.

RIVERA, Raúl

1966 Libro del cabildo de la Ciudad de San Juan de la Frontera de Huamanga (1539-1547). Lima: Ediciones Casa de la Cultura. 